OPEN ACCESS

Edited by:

Takashi Sato,

Tokyo University of Pharmacy and Life

Sciences, Japan

Reviewed by:

Suresh Kumar Mohankumar,

JSS College of Pharmacy, India

You Yun,

China Academy of Chinese Medical

Sciences, China

*Correspondence:

Ahmed Z. El-Hashim

ahmed.elhashim@ku.edu.kw

Specialty section:

This article was submitted to

Ethnopharmacology,

a section of the journal

Frontiers in Pharmacology

Received: 14 April 2020 Accepted: 27 August 2020

Published: 02 October 2020

Citation:

El-Hashim AZ, Khajah MA, Orabi KY,

Balakrishnan S, Sary HG and

Abdelali AA (2020) Onion Bulb Extract Downregulates EGFR/ERK1/2/AKT

Signaling Pathway and Synergizes With Steroids to Inhibit Allergic Inflammation.

Front. Pharmacol. 11:551683. doi: 10.3389/fphar.2020.551683

\section{Onion Bulb Extract Downregulates EGFR/ERK1/2/AKT Signaling Pathway and Synergizes With Steroids to Inhibit Allergic Inflammation}

\author{
Ahmed Z. El-Hashim ${ }^{1 *}$, Maitham A. Khajah ${ }^{1}$, Khaled Y. Orabi ${ }^{2}$, Sowmya Balakrishnan ${ }^{1}$, \\ Hanan G. Sary ${ }^{2}$ and Ala A. Abdelali ${ }^{1}$ \\ ${ }^{1}$ Department of Pharmacology \& Therapeutics, Faculty of Pharmacy, Kuwait University, Kuwait City, Kuwait, ${ }^{2}$ Department of
Pharmaceutical Chemistry, Faculty of Pharmacy, Kuwait University, Kuwait City, Kuwait
}

The treatment of allergic diseases, such as asthma, with both conventional and novel therapies presents a challenge both in terms of optimal effect and cost. On the other hand, traditional therapies utilizing natural products such as onion have been in use for centuries with demonstrated efficacy and safety but without much knowledge of their mechanims of action. In this study, we investigated if the anti-inflammatory effects of onion bulb extract (OBE) are mediated via the modulation of the EGFR/ERK1/2/AKT signaling pathway, and whether OBE can synergise with steroids to produce greater anti-inflammatory actions. Treatment with OBE inhibited the house dust mite (HDM)-induced increased phosphorylation of EGFR, ERK1/2 and AKT which resulted in the inhibition of HDMinduced increase in airway cellular influx, perivascular and peribronchial inflammation, goblet cell hyper/metaplasia, and also inhibited ex vivo eosinophil chemotaxis. Moreover, treatment with a combination of a low dose OBE and low dose dexamethasone resulted in a significant inhibition of the HDM-induced cellular influx, perivascular and peribronchial inflammation, goblet cell hyper/metaplasia, and increased the pERK1/2 levels, whereas neither treatment, when given alone, had any discernible effects. This study therefore shows that inhibition of the EGFR/ERK1/2/AKT-dependent signaling pathway is one of the key mechanisms by which OBE can mediate its anti-inflammatory effects in diseases such as asthma. Importantly, this study also demonstrates that combining OBE with steroids results in significantly enhanced anti-inflammatory effects. This action may have important potential implications for future asthma therapy.

Keywords: onion (Allium cepa Hysam), asthma, signalling, steroids, synergisctic effects 


\section{INTRODUCTION}

Natural products have been the cornerstone of therapeutic agents for millennia and more recently an important source of therapeutic drugs with unique structural diversity and pharmacological actions (Newman and Cragg, 2016). Many therapeutic agents currently in use in several therapeutic areas such as cardiovascular, oncology, transplantation are natural products or their derivatives such as digoxin, vincristine, and cyclosporine, respectively. However, their use as pharmaceutical agents has waned over the last few decades in the face of advances in combinatorial chemistry and biopharmaceutical technology, the latter supplying the majority of the top ten block buster drugs in the market in 2018 (Brown et al., 2017). Indeed, more than $70 \%$ of the world's population use herb-based medicines for primary healthcare (Newman and Cragg, 2016). A recent study has also reported that approximately $60 \%$ of asthma patients in the UK have used herbal remedies for their asthma (Clark et al., 2010). These findings suggest a strong held belief that natural products not only have therapeutic benefit in a wide range conditions, but that they are also safe.

Inflammatory-based diseases, such as asthma, present a global healthcare challenge. Worldwide prevalence of asthma has been estimated to range from $1 \%$ to as high as $18 \%$ in different populations, affecting up to 300 million people worldwide (Nunes et al., 2017; WHO, 2019) with increasing prevalence particularly among children (GINA, 2019). It is currently the most common chronic respiratory disease in children and costs over a $£ 1$ billion per year in some healthcare systems in Europe (Harrison, 2015). There is also good evidence that food allergy and eczema are rising, in parallel to asthma, and have been described as a "second wave" of allergy epidemic particularly in children (Prescott and Allen, 2011). While the mechanisms of asthma still remain unclear, it is well recognized that chronic airway inflammatory disease is central to its pathogenesis and is mediated by inflammatory cells such as mast cells and eosinophils and is driven by specific Th2 and Th17 lymphocytes, cytokines, and chemokines (Massoud et al., 2016; Athari, 2019).

There have been several recent studies demonstrating that pathogenic EGF/EGFR-dependent signaling through EGF and other EGFR ligands, such as amphiregulinin, is increased in asthma (Acciani et al., 2016; Ha and Rogers, 2016). EGFR expression has been reported to be weak or absent in healthy individuals but is significantly increased in the airway epithelium of not only asthmatics (Puddicombe et al., 2000; Takeyama et al., 2001a; Takeyama et al., 2001b; Polosa et al., 2002), but also in patients with COPD (de Boer et al., 2006) and cystic fibrosis patients (CF) (Burgel et al., 2007). Furthermore, in a recent clinical study conducted using ex vivo lung tissue from patients with COPD, the EGFR inhibitor BIBW 2948 showed some efficacy in inhibiting EGFR phosphorylation and a tendency toward reducing mucous cell metaplasia. More importantly, a positive correlation between EGFR immunoreactivity and MUC5AC mucin staining was noted when bronchial biopsies from healthy volunteers and subjects with mild-to-moderate asthma were compared, suggesting a causal relationship (Puddicombe et al., 2000). Also, areas of epithelial damage in asthmatic patients exhibited a strong EGFR immunoreactivity suggesting that EGFR activation plays an important role in the epithelial damage/repair process in asthma (Puddicombe et al., 2000). Of interest also is that a positive correlation between mucin and EGFR staining has been shown in the small airway of CF patients (Burgel et al., 2007). Thus, increased EGFR expression is a consistent finding not only in asthma but across several disease states. Moreover, preclinical animal models have also demonstrated a strong role for EGFR in asthma. We and others have shown, using an allergic model of inflammation, that EGFR inhibitors, such as AG1478 or gefitnib, significantly reduce eosinophil recruitment, airway inflammation, airway hyperresponsiveness (AHR), and goblet cell hyper/metaplasia, thus, underscoring the importance of this signaling pathway in asthma pathogenesis (Tamaoka et al., 2008; Le Cras et al., 2011; Song H. N. et al., 2016; El-Hashim et al., 2017). Furthermore, we have also reported that ERK1/2 and AKT are downstream signaling molecules of EGFR activation (El-Hashim et al., 2017). Therefore, both clinical and preclinical studies clearly establish an important role for EGFR-dependent signaling in inflammatory-based diseases.

While the combination of inhaled corticosteroids (ICS) and long-acting beta-agonists (LABA) is a main treatment advocated by most asthma guidelines (O’Byrne et al., 2001; GINA, 2019), a significant number of patients are poorly compliant with inhaled treatments and remain under-controlled (Sherman et al., 2001). Furthermore, severe asthmatics require treatment with moderate to high doses of steroids (Carr and Kraft, 2017). This is associated with a significant side effect profile (Pinto et al., 2013). Therefore, it would be more advantageous if the asthma therapeutic goals can be achieved at lower doses of steroids since the side effects would be minimal. Synergism is a phenomenon whereby combination of drugs produces a greater effect than when each drug is given alone (Jia et al., 2009). This phenomenon is useful when low doses of efficacious drugs are combined as they produce a superior effect but with fewer side effects. Indeed, this has been demonstrated with ICS and several drug classes such as LABA and anti-leukotrienes (Beasley et al., 2019). However, no study has tested if synergism occurs between steroids and natural products within the context of inflammatory based diseases such as asthma.

Novel monoclonal antibody-based therapy, in inflammatory disease management, has made an impact on disease control. For example, the anti-IgE antibody, omalizumab, has been used as a steroid sparing drug in patients with severe asthma, but unfortunately its use is limited (Plosker and Keam, 2008) due to a high frequency of anaphylactic reaction and serum sickness (Harrison et al., 2015) and lack of cost-effectiveness. Similarly, the use of the newly introduced anti-IL5 antibodies such as mepolizumab and benralizumab is limited to severe asthmatics with a high eosinophilic component. However concerns have been raised regarding their cost-effectiveness (Agache et al., 2020). Despite the recent market increase in therapeutic agents that selectively target specific molecules, it is unlikely that the blockade 
of individual mediator signaling pathways would result in optimal therapeutic outcomes in asthma, and monoclonal based therapy would certainly be beyond the financial reach of most asthma patients in the developing world due to their high cost.

Allium cepa L. (Family Amaryllidaceae) is one of the most commonly consumed vegetables and has also been used for medicinal purposes for numerous ailments such as ulcer wounds, scars, dysentery, inflammation, hypertension and also in respiratory conditions such as cough, asthma, and bronchitis (Lanzotti, 2006; Upadhyay, 2016; Zeng et al., 2017). Onion bulb extract (OBE) has also been shown to effectively reduce airway inflammation, IL4, and IgE levels and induces oxidation in animal models of asthma (Oliveira et al., 2015; Marefati et al., 2018). Thiosulfinates (TS) and cepaenes (CS), isolated from onions and/or synthesized, were also shown to have dosedependent inhibitory effects on both cyclooxygenase and 5lipoxygenase activity (Dorsch et al., 1990; Wagner et al., 1990) and inhibit in vitro chemotaxis of human granulocytes induced by formyl-methionine-leucine-phenylalanine (WKYMvm) (Dorsch et al., 1990). In this regard, it is of interest to note that many of the previous studies that assessed the effects of onion extract have used ovalbumin as the allergenic material to induce airway inflammation. However, the use of ovalbumin has recently been questioned on the basis that it is not clincally relevant, and therefore studies using allergens such as house dust mite or Alternaria alternata, that simulate clincal asthma more closely (Gorska, 2018), are necessary in order to better assess the effects of onion extract in animal models.

The EGFR/ERK1/2/AKT signaling pathway has been recently shown to be an important signaling pathway, in both clincial and preclinical studies. However, whether the EGFR/ERK1/2/AKT signaling pathway is a target for OBE in a clincially relevant animal model of allergic asthma, is not known. Also whether OBE synergizes with steroids has not been studied previously. In this study, using a clincially relevant allergen (HDM), we investigated 1) whether the EGFR/ERK1/2/AKT signaling pathway is modulated by OBE, and 2) if OBE synergizes with dexamethasone to result in a greater anti-inflammatory action.

\section{METHODS}

\section{Acquisition of the Plant Material}

Fresh red onion bulbs were bought from the local market. The plant was identified as Allium cepa, and a voucher specimen, number KOE-010, was deposited at the herbarium of Kuwait University (KTUH), College of Science, Kuwait.

\section{Extraction of Onion Bulbs}

About $20 \mathrm{~kg}$ of fresh red onion was peeled, coarsely cut, and percolated three times, each using $10 \mathrm{~L}$ of dichloromethane. The dichloromethane layers of the percolates were separated from the aqueous layer, dried over anhydrous sodium sulphate, and then evaporated in vacuo till dryness to obtain brownish syrupy residue. This extraction process was repeated as needed. The treatment stock solution was prepared using the residue and PBS as a vehicle.

\section{GC-MS Analysis}

Dichloromethane extract of onion bulbs ( $1 \mu \mathrm{l}$ sample size) was analyzed on a Thermo high resolution gas chromatographymass spectrometer Double Focusing Sector system (GC-MS DFS) fitted with a DB-5MS capillary column with $0.25 \mu \mathrm{m}$ film thickness, $30 \mathrm{~m}$ length and $0.25 \mathrm{~mm}$ inner diameter, using helium as a carrier gas with a flow rate of $0.8 \mathrm{ml} / \mathrm{min}$. The operating conditions were as follows: splitless injector with port temperature $250^{\circ} \mathrm{C}$, detector temperature $280^{\circ} \mathrm{C}$, and program temperature from 50 to $250^{\circ} \mathrm{C}$ at the rate of $6^{\circ} \mathrm{C} / \mathrm{min}$ with $10 \mathrm{~min}$ hold time, and from 250 to $300^{\circ} \mathrm{C}$ at the rate of $10^{\circ} \mathrm{C} / \mathrm{min}$ with 6 min hold time. The MS conditions were as follows: electron impact ionization mode, ionization energy $70 \mathrm{eV}$, ion source temperature $175^{\circ} \mathrm{C}$, scan range $m / z 40-900 \mathrm{Da}$. The qualitative identification of the compounds was based on computer matching with NIST MS Search 2.0 library and by comparison with data in the literature (Mondy et al., 2001; Gitin et al., 2014; Abdel-Lateef et al., 2018; Fredotovic et al., 2020).

\section{Animals}

Male BALB/c mice (6-8 weeks old, average weight $25 \mathrm{~g}$ ) were used in this study. All studies involving animals were in accordance with the ARRIVE guidelines for reporting experiments involving animals. All experimental protocols were approved by the Animal Welfare and Use of Laboratory Animals Committee in the Health Sciences Center, Kuwait University and were carried out in accordance with the EU Directive 2010/63/EU for animal experiments and the National Institutes of Health guide for the care and use of Laboratory animals (NIH Publications No. 8023, revised 1978). Animals were maintained under temperature-controlled conditions with an artificial $12 \mathrm{~h}$ light/dark cycle and were allowed standard chow and water ad libitum.

\section{Immunization and Intranasal Challenge and Drug Treatment Protocols Protocol for Prophylactic Treatment Experiments}

Seven treatment groups (A-G, 9-15 animals per group) were established to determine whether OBE if given prophylactically inhibits the HDM-induced asthma phenotype. All mice were immunized once by intraperitoneal (i.p.) injection of $40 \mu \mathrm{g} \mathrm{HDM}$ in $0.2 \mathrm{ml}$ of alu-Gel-S (Alu-Gel-S; SERVA Electrophoresis $\mathrm{GmbH}$ ) on day 0 . Mice were subsequently challenged for 3 days, days 14,17 , and 18 with HDM or PBS in the case of the control group. Mice in groups $A(n=11)$ and $B(n=13)$ were pretreated intraperitoneally with $0.2 \mathrm{ml}$ of the drug vehicle, $1 \mathrm{~h}$ before each intranasal challenge with $\mathrm{PBS}$ and HDM, respectively. In the same manner, groups $C(n=10), D(n=9), E(n=10)$, and $F$ $(\mathrm{n}=15)$ were pretreated with the same volume of OBE at 10 , 30,60 , and $100 \mathrm{mg} / \mathrm{kg}$, respectively, and group $\mathrm{G}(\mathrm{n}=11)$ with dexamethasone $(3 \mathrm{mg} / \mathrm{kg}), 1 \mathrm{~h}$ before each intranasal challenge with HDM (Figure 1).

$24 \mathrm{~h}$ after the last intranasal challenge, animals were sacrificed with an overdose of halothane; bronchoalveolar lavage (BAL) was performed to obtain BAL fluid, and then the lungs were excised for preparation for histology, Western Blot (WB), and 


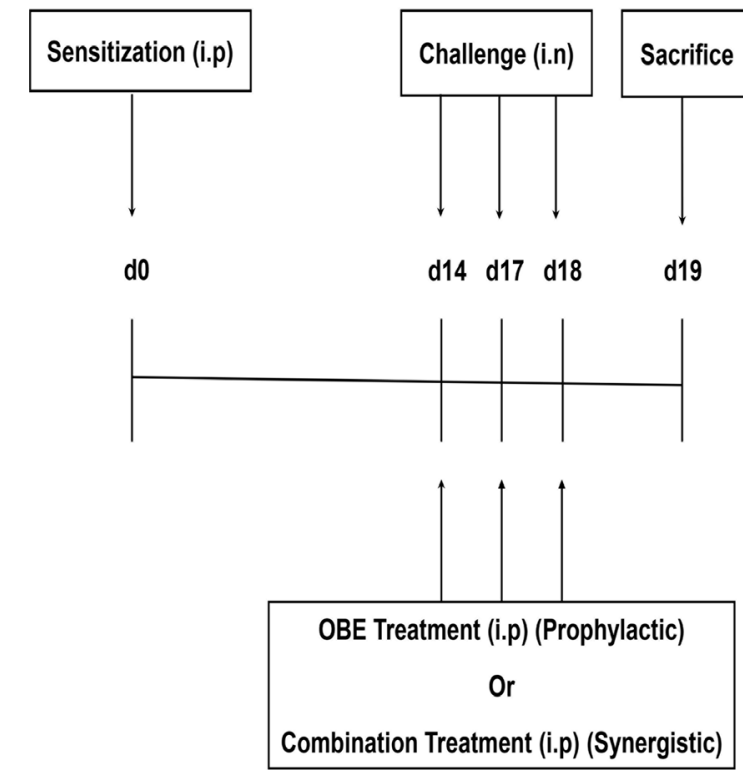

FIGURE 1 | Schemactic representation of the immunization and the treatment protocol used for boh the prophylactic and synergistic studies.

immunofluorescence (IF) studies. In another separate group of animals, airway responsiveness was measured. For the histology/ $\mathrm{WB} / \mathrm{IF}$ studies, the OBE dose of $60 \mathrm{mg} / \mathrm{kg}$ was selected to represent the prophylactic approach as it gave an optimum effect.

\section{Protocol for Synergistic Treatment Experiments}

Six treatment groups (A-F, 9-11 animals per group) were established to determine whether combining OBE and dexamethasone would results in synergistic anti-inflammatory actions. Mice in groups A $(n=9)$ and $B(n=11)$ were pretreated intraperitoneally with $0.2 \mathrm{ml}$ of the drug vehicle $1 \mathrm{~h}$ before each intranasal challenge with PBS and HDM, respectively. In the same manner, groups $C(n=11), D(n=7), E(n=11)$, and $F(n=$ 9) were pretreated with the same volume of OBE at $30 \mathrm{mg} / \mathrm{kg}$ (OBE 30), OBE at $30 \mathrm{mg} / \mathrm{kg}$ in combination with dexamethasone $(\mathrm{DEX})$ at $0.5 \mathrm{mg} / \mathrm{kg}(\mathrm{OBE} 30+\mathrm{DEX} 0.5), 0.5 \mathrm{mg} / \mathrm{kg}$ (DEX 0.5 $\mathrm{mg}$ ) and $3 \mathrm{mg} / \mathrm{kg}$ (DEX $3 \mathrm{mg}$ ), respectively, $1 \mathrm{~h}$ before each intranasal challenge with HDM. Treatment with OBE and/or dexamethasone was also repeated on days 14,17 , and 18 (Figure 1).

\section{Bronchoalveolar Lavage Fluid Cell Counts and Lung Histology}

BAL fluid was collected by cannulating the trachea and washing the lungs with saline solution $(0.3 \mathrm{ml} \times 4$ each $)$ after sacrificing the animals with an over dose of halothane. The BAL cells were then counted using a particle-size counter (Z1 Single Threshold; Beckman Coulter), and cytosmears were prepared for differential count. The cells were stained with Diff-Quik, and a differential count of 200 cells was performed using standard morphologic criteria. Results are expressed as total cell count $/ \mathrm{ml}$ and as total macrophages, lymphocytes, neutrophils, and eosinophils/ml in
BAL fluid. For histological assessment, segments of the lung tissue were removed and fixed in $10 \%$ buffered formalin, embedded in paraffin wax and sectioned into 5 - $\mu$ m-thick slices. The sections were processed and stained separately with $\mathrm{H} \& \mathrm{E}$ stain and periodic acid-Schiff (PAS) according to standard methods as previously described (El-Hashim et al., 2017). Sections were examined under light microscope and the severity of pathologic changes scored independently by two experienced histologists unfamiliar with the slides. Score coding was as follows: $(1=$ normal, $2=$ mild, $3=$ moderate, $4=$ severe and 5 = highly severe).

\section{Measurement of Airway Responsiveness}

Airway responsiveness was measured $24 \mathrm{~h}$ after last HDM or PBS challenge, using a separate set of animals using the Buxco FinePointe series RC site (DSI, Wilmington, NC) as described previously (Queto et al., 2010; Ezeamuzie et al., 2014; Correa et al., 2017). Briefly, mice were anesthetized with an intraperitoneal injection of ketamine/xylazine $(1: 0.1 \mathrm{mg} / \mathrm{kg})$ cocktail and tracheotomized with a steel 18-gauge cannula. Mice were then mechanically ventilated at a rate of 150 breaths $/ \mathrm{min}$ and a tidal volume of $0.15 \mathrm{ml}$ using a computerized small animal ventilator (FinePointe site). Following a $5 \mathrm{~min}$ period of stabilization and administration of PBS, airway resistance was measured by exposing mice to aerosolized methacholine (6.25-50.0 $\mathrm{mg} / \mathrm{ml}, 5 \mu \mathrm{l}$ per delivery) delivered by an aerogen nebulizer and reported as total lung resistance $\left(R_{\mathrm{L}}\right)\left(\mathrm{cm} \mathrm{H}_{2} \mathrm{O}\right.$ per $\mathrm{ml} / \mathrm{s}$ ).

\section{Immunofluorescence}

Lung tissues were processed as described above. Immunofluorescence was performed as previously described (Khajah et al., 2016). In short, lung sections were incubated in a blocking solution ( $5 \%$ bovine serum albumin (BSA) $+0.3 \%$ Triton X-100 in PBS) for $1 \mathrm{~h}$ and were subsequently incubated overnight at $4^{\circ} \mathrm{C}$ with primary antibodies [p-EGFR (Tyr1068) (Rabbit; Cat. No. 3777S), pAKT (Ser 473) (Rabbit; Cat. No. 9271L) and pERK1/2 (Thr202/Tyr204) (Rabbit; Cat. No. 9101L) (1:25-1:800 dilution) or only 1\% BSA (for negative control); Cell Signaling, USA], diluted in 1\% blocking solution. $24 \mathrm{~h}$ later, sections were washed and incubated with secondary antibody conjugated to Alexa Fluor 555 (Goat anti rabbit SFX kit; Life Technologies, USA, 1:400 dilution) for $2 \mathrm{~h}$ at room temperature in the dark. Following several washes in PBS, sections were stained with 4', 6 diamidino-2-phenylindole and mounted. Images were then captured on a ZEISS LSM 700 confocal microscope and fluorescence intensity estimated in defined fields using Image J software package. The laser setting and photo processing were equal among the different treatment groups for each protein. $40 \times$ magnification for the tested molecules was equally modified in terms of sharpness and contrast to show localization of the phospho-proteins in the lung tissue.

\section{Western Blotting}

Appropriate lobes from the dissected lungs of the mice were snap-frozen in liquid nitrogen and stored at $-80^{\circ} \mathrm{C}$. Following 
that, the tissue samples were defrosted in ice then transferred to lysis buffer ( $\mathrm{pH} 7.6$ ) containing $50 \mathrm{mM}$ Tris-base, 5 mM EGTA, $150 \mathrm{mM} \mathrm{NaCl}, 1 \%$ Triton 100, $2 \mathrm{mM} \mathrm{Na}_{3} \mathrm{VO}_{4}, 50 \mathrm{mM} \mathrm{NAF}, 1$ mM PMSF, $20 \mu \mathrm{M}$ phenyl arsine, $10 \mathrm{mM}$ sodium molybdate, 10 $\mu \mathrm{g} \mathrm{ml}^{-1}$ leupeptin and $8 \mu \mathrm{g} \mathrm{ml}^{-1}$ aprotinin. Using a homogenizer, the tissues were homogenized for $10 \mathrm{~s}$, three times. Samples were allowed to lyse completely by incubation on ice for $30 \mathrm{~min}$. The lysates were then centrifuged at $13,000 \mathrm{rpm}$ for $10 \mathrm{~min}$ at $4^{\circ} \mathrm{C}$ and the supernatants collected, and protein concentrations were estimated by Bio-Rad Bradford Protein Assay (Bio-Rad, Hercules, CA, USA). Aliquots containing equal amounts of protein were subjected to SDS-PAGE and transferred electrophoretically onto nitrocellulose membrane (Schleicher \& Schuell, Dassel, Germany). The membranes were blocked with 5\% BSA and then incubated with ERK1/2 (137F5) (Rabbit; Cat. No. 4695S), pERK1/2 (Thr202/Tyr204) (Rabbit; Cat. No. 9101L) and $\beta$-actin antibody (Cell Signaling Technology, Boston, MA, USA; $1 / 1,000$ dilution) (used as loading control, $1: 1,000$ in 5\% BSA) at $4^{\circ} \mathrm{C}$ overnight. Membranes were incubated with appropriate secondary antibodies conjugated to horseradish peroxidase (Amersham, Buckinghamshire, UK) to detect phosphorylated form of ERK1/2 $(42 / 44 \mathrm{kDa})$, or total form of actin $(45 \mathrm{kDa})$. The immunoreactive bands were detected with Super Signal Chemiluminescent Substrate (Immuno Cruz Western blotting luminal reagent SC-20428, Santa Cruz Biotechnology) utilizing a Kodak autoradiography film (Care stream Biomax Xarfil 1660760). Images were then analyzed and quantified and the data were normalized to $\beta$-actin levels. The experiment was run twice with lung samples from three different mice in each treatment group (pooled) in each run.

\section{Measurement of Lung Cytokines}

Lung tissues from mice were collected and stored at $-80^{\circ} \mathrm{C}$. The amount of total protein was determined by Bradford analysis using the Bio-Rad Protein Assay reagent. The relative changes of different cytokines and chemokines were detected using Proteome Profiler ${ }^{\mathrm{TM}}$ Mouse Cytokine Array Kit (Catalog \# ARY006, R\&D Systems, Inc., Minneapolis, USA). The procedure was done in line with the manufacturer's protocols and as recently described (Khajah et al., 2019).

\section{Isolation of Human Blood Eosinophils}

For this experiment, fresh blood was obtained from healthy individuals with no history of allergic disease and had not taken any medication in the last $72 \mathrm{~h}$ after receiving their informed consent. The methods and protocol for these experiments were performed in accordance with and approved by the "Ethical Committee of the Faculty of Medicine, Kuwait University". Granulocytes were isolated from heparinized $(10 \mathrm{IU} / \mathrm{ml})$ blood by erythrocyte sedimentation, followed by percoll gradient centrifugation as reported recently (Ezeamuzie et al., 2014). Eosinophils were separated using negative selection with the immunomagnetic method as previously described (Hansel et al., 1991). The eosinophil purity was checked by differential count of a Wright-Giemsa stained cytosmear and was routinely $>98 \%$.
Viability was determined by Trypan blue exclusion and exceeded $98 \%$.

\section{Boyden Chamber Assay for Eosinophil Chemotaxis}

Peripheral blood derived eosinophils were used for chemotaxis assay utilizing a Boyden chamber as previously described (Gomez-Cambronero et al., 2003). Purified naïve eosinophils $\left(2 \times 10^{5}\right)$ were then placed in the upper wells, and $500 \mu \mathrm{l}$ of BAL fluid derived from mice challenged with PBS (vehicle) or with HDM, pretreated ex-vivo with either vehicle or OBE (100 and $1,000 \mathrm{ng} / \mathrm{ml})$, were placed in the lower wells $\left(37^{\circ} \mathrm{C} / 5 \% \mathrm{CO}_{2}\right)$ and eosinophils allowed to migrate for $1 \mathrm{~h}$. The transmigrated eosinophils were determined by counting under the microscope by using a hemocytometer.

\section{Statistical Analyses}

All numerical values were expressed as means \pm SEM. Total cell counts represent the number of cells/ml of BAL fluid. Differential cell counts represent the absolute number of each cell type $/ \mathrm{ml}$ of BAL fluid. Absolute $\mathrm{R}_{\mathrm{L}}$ values were computed and were used as an index of airway responsiveness. For the histopathological assessment, a semi-quantitative 5-level lung pathology score was used to grade the degree of inflammation in each microscopic field at $20 \times$. All data were initially assessed for normality. Oneway analysis of variance (ANOVA) test followed by Bonferroni post hoc was used to compare differences between individual groups for both total and differential cell count as well as histopathological data and the immunofluorescence data for both the prophylactic and the synergistic studies. A two-way repeated measure analysis of variance followed by a Bonferroni post hoc test was used for the airway responsiveness data. The mean difference was considered as significant at a probability level of less than 0.05. All analyses were performed using GraphPad Prism.

\section{RESULTS}

\section{Extraction of Onion Bulbs}

The extraction process was repeated four times to afford $7.5 \mathrm{~g}$ $(0.038 \%$ yield) of brownish syrupy residue (Figure 2 ).

\section{GC-MS Analysis of OBE}

Dichloromethane extract of Allium cepa bulb (OBE) was analyzed to identify different compounds and confirm the identity of the plant. The identified compounds and their mass spectral data are listed in Table 1. The major compound identified in the extract was shown to be the sulfur-containing compounds dipropyl disulfide, dipropyl trisulfide, and propylpropane thiosulfonate. Other sulfur compounds were also identified but at lesser quantities. Figure $\mathbf{2 A}$ shows the TIC of OBE where different 28 peaks are shown. Furthermore, Figure 2B shows the fragmentation patterns of some of these compounds. The identity of these compounds was confirmed via 


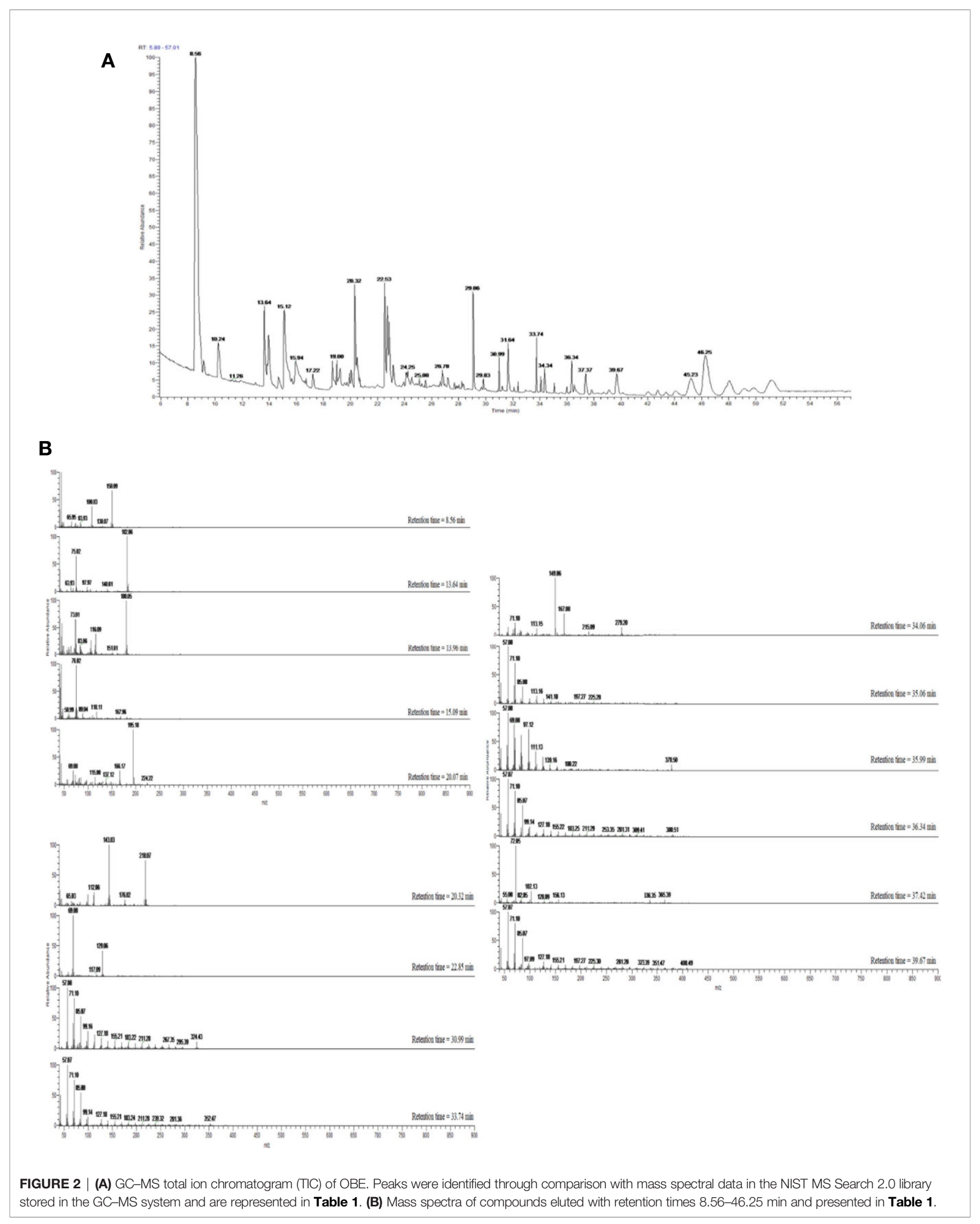


TABLE 1 | Compounds identified in Allium cepa bulb extract.

\begin{tabular}{lcc}
\hline Identified Compounds $^{\mathbf{a}}$ & $\begin{array}{c}\text { Retention timet }_{\mathbf{r}} \\
\text { (min) }\end{array}$ & $\begin{array}{c}\text { Area } \\
\text { (\%) }\end{array}$ \\
\hline Dipropyl disulfide & 8.56 & 45.93 \\
Dipropyl trisulfide & 13.64 & 3.16 \\
3,5-Diethyl-1,2,4-trithiolane & 13.96 & 1.88 \\
Propylpropane thiosulfonate & 15.09 & 5.07 \\
1,5-Dithiaspiro[5.6]dodecan-7-ol & 20.32 & 3.46 \\
Methyl-2,6-anhydro-3,4,7-tridesoxy-1-erythro- & 22.85 & 1.25 \\
hept-2-enulonate & & \\
Tricosane & 30.99 & 0.63 \\
Pentacosane & 33.74 & 1.37 \\
1,2-Benzenedicarboxylic acid & 34.06 & 0.34 \\
Hexacosane & 35.06 & 0.3 \\
1-Heptacosanol & 35.99 & 0.18 \\
Nonacosane & 36.34 & 1.2 \\
Nonacosane & 39.67 & 1.88 \\
Tetratriacontane & 45.23 & 4.09 \\
\hline
\end{tabular}

aldentified by matching with mass spectral data in the NIST MS Search 2.0 library stored in the GC-MS system, and comparison with data reported in the literature.

a direct comparison and matching with the stored spectra in the GC-MS system.

\section{Effect of OBE on HDM-Induced Inflammatory Cell Influx}

In these experiments, we evaluated the effect of OBE on HDMinduced total and differential cell influx. Our findings show that HDM-sensitized and challenged animals (HDM group) developed a significant increase in total cell count $(1.3 \pm 0.3$ vs $11.0 \pm 2.0 \times$ $10^{5}$ cells $\left./ \mathrm{ml}\right)$ as well as in lymphocytes $(0.03 \pm 0.01$ vs $1.9 \pm 0.6 \times$ $10^{5}$ cells $\left./ \mathrm{ml}\right)$ and eosinophils (0.04 \pm 0.02 vs $4.9 \pm 0.6 \times 10^{5}$ cells/ $\mathrm{ml}),(\mathrm{P}<0.05$; Figures 3A, B, $\mathrm{n}=9-15), 24 \mathrm{~h}$ after the last HDM challenge compared to the control group. Prophylactic treatment with $\mathrm{OBE}(10,30,60$, and $100 \mathrm{mg} / \mathrm{kg})$ dose-dependently inhibited the HDM-induced increase in the total cells and was significant at the doses of 60 and $100 \mathrm{mg} / \mathrm{kg}(3.3 \pm 0.7$ and $2.2 \pm 0.4 v s 11.0 \pm 2.0$ $\times 10^{5}$, respectively, $\mathrm{P}<0.05$; Figure $\left.3 \mathrm{~A}, \mathrm{n}=9-15\right)$ and were comparable to the dexamethasone (DEX) group (used as a positive control). Moreover, OBE treatment also inhibited the HDMinduced increase in lymphocytes $\left(0.4 \pm 0.2\right.$ vs $1.9 \pm 0.6 \times 10^{5}$ cells $/ \mathrm{ml}, \mathrm{P}<0.05$; Figure 3B, $\mathrm{n}=9-15)$ and eosinophils $(0.6 \pm 0.2$ vs $4.9 \pm 0.6 \times 10^{5}$ cells $/ \mathrm{ml}, \mathrm{P}<0.05$; Figure $\left.3 \mathrm{~B}, \mathrm{n}=9-15\right)$.

\section{Effect of OBE on HDM-Induced Histopathological Changes}

$\mathrm{H} \& \mathrm{E}$ and PAS stained lung sections from control mice (PBS group) showed normal histology (Figures 4A, B). In contrast, lung sections from mice challenged with HDM showed consistently marked and severe perivascular and peribronchial inflammatory cell infiltration (cellular infiltration score, HDM vs PBS, $4.2 \pm 0.2$ $v s 1.0 \pm 0.07)$ and increase in bronchial mucus production and goblet cell hyper/metaplasia (mucous intensity score, HDM vs PBS, $4.1 \pm 0.3$ vs $1.0 \pm 0.02)$ demonstrating a marked degree in airway remodeling $(\mathrm{P}<0.05$; Figures $4 \mathbf{A}-\mathbf{D}, \mathrm{n}=3-6)$. However, lung sections from OBE-treated mice $(60 \mathrm{mg} / \mathrm{kg})$ showed a significantly lower score of the histopathological parameters that were assessed (cellular infiltration score; $2.7 \pm 0.3$ vs $4.2 \pm 0.2$, and
A

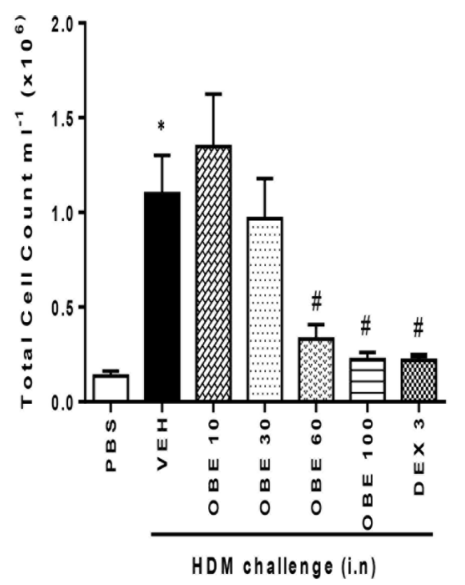

B

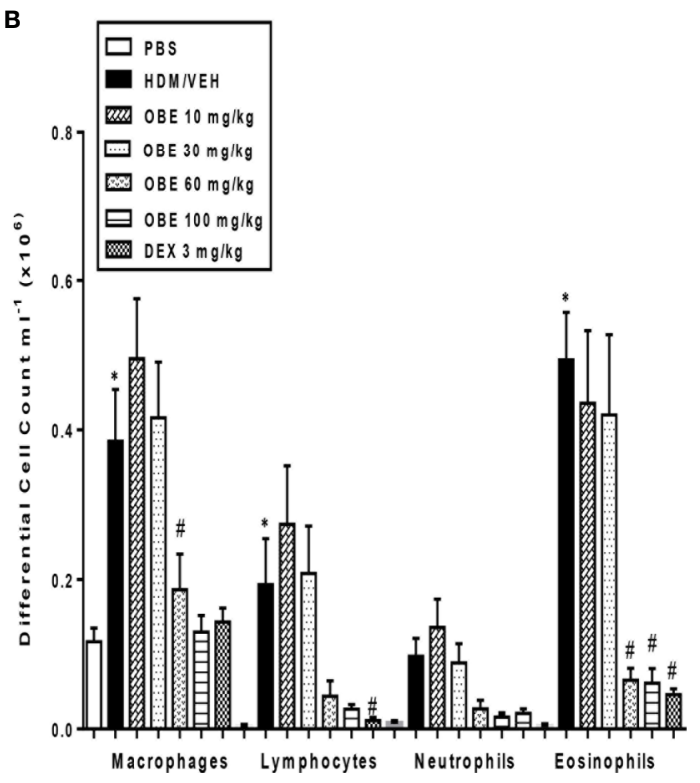

FIGURE 3 | Effect of OBE, 10, 30, 60, and 100 mg/kg (i.p.) on HDM-induced increase in (A) total cell and (B) differential cell count. OBE treatment resulted in a dose-dependent inhibition of total and eosinophil numbers. Data are expressed as mean \pm SEM $(n=9-15){ }^{*} \mathrm{P}<0.05$ vs PBS group, ${ }^{\#} \mathrm{P}<0.05$ vs HDM group.

mucous intensity score; $2.3 \pm 0.5$ vs $4.1 \pm 0.3$ ), achieving almost normal histological appearance that was very similar to the dexamethasone treatment group $(\mathrm{P}<0.05$; Figures $4 \mathrm{~A}-\mathrm{D}, \mathrm{n}=$ $3-6)$.

\section{Effect of OBE on HDM-Induced Phosphorylation of EGFR, ERK1/2, and AKT as Determined by Immunofluorescence}

Our findings show that HDM challenge induced a significant increase of about 3.0, 2.3 and 2.4-fold in the phosphorylation of EGFR, ERK1/2, and AKT, respectively, compared to PBS control as detected by immunofluorescence $(\mathrm{P}<0.05$; Figures $\mathbf{5 A}-\mathbf{C}, \mathrm{n}=$ 
A
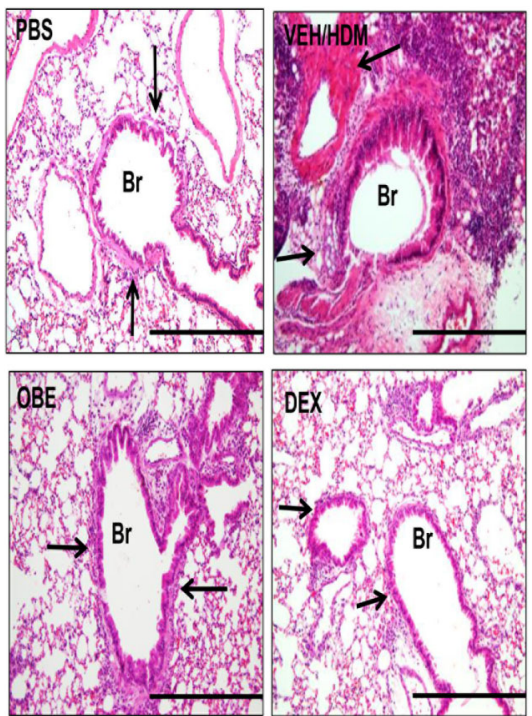

c

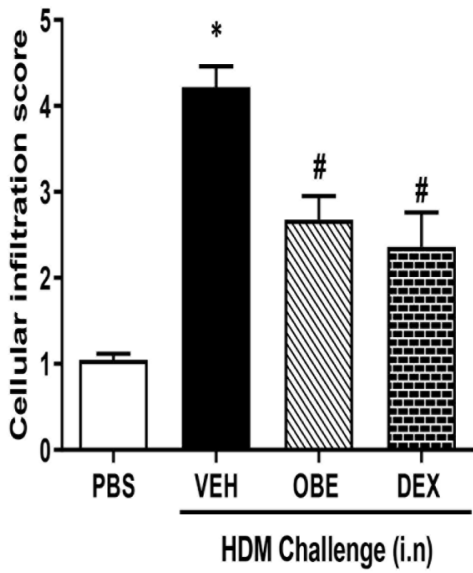

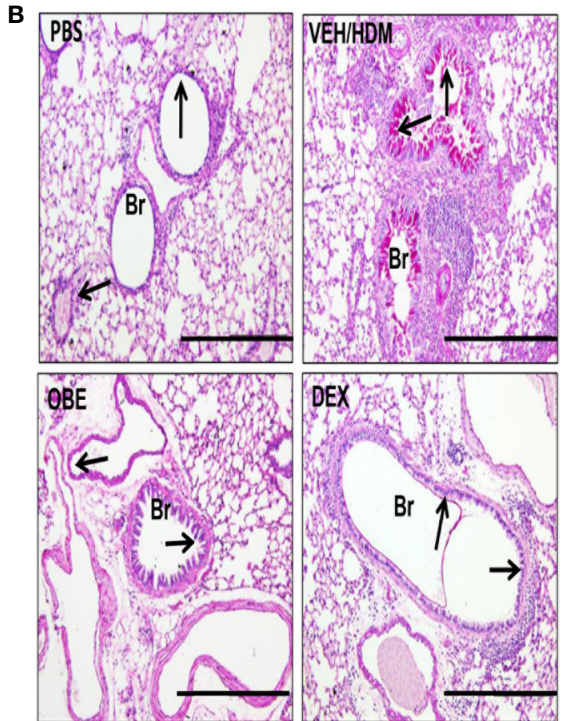

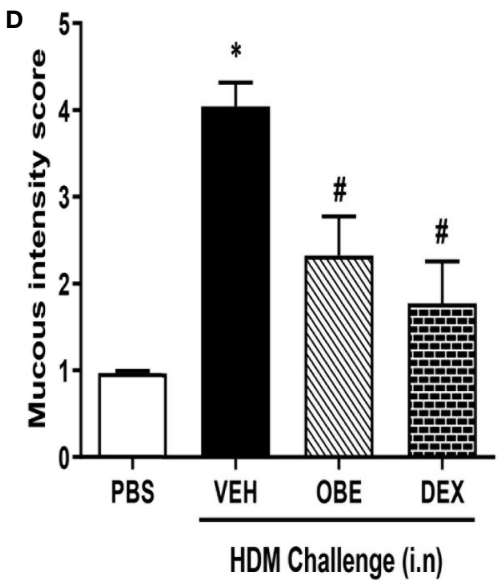

FIGURE 4 | Effect of OBE (60 mg/kg; i.p.) on HDM-induced histopathological changes: (A) representative low-magnification light photomicrographs displaying (A) H\&E and (B) PAS staining of whole lung samples from control PBS-challenged mice (PBS), HDM-challenged mice (HDM), HDM-challenged mice pretreated with OBE (60 mg/kg; i.p.) (OBE) and HDM-challenged mice pretreated with dexamethasone (3 mg/kg; i.p.) (DEX), scale bar = 200um. Graphs shows (C) cellular infiltration and (D) mucous intensity score for H\&E and PAS staining, respectively. OBE treatment resulted in a significant decrease in both peribronchial and perivascular inflammatory cell infiltrations and bronchial mucus production and goblet cell hyper/metaplasia compared with HDM-challenged vehicle treated mice. Data are expressed as mean \pm SEM $(n=3-6)$. ${ }^{*} \mathrm{P}<0.05$ vs PBS group, ${ }^{\#} \mathrm{P}<0.05$ vs HDM group.

3-5). Negative control shows no non-specific staining (data not shown). Treatment with OBE (60 mg/kg) significantly inhibited the HDM-induced phosphorylation of all proteins $(\mathrm{P}<0.05)$ and was comparable to the inhibition obtained in the dexamethasone treatment group $(\mathrm{P}<0.05$, Figures $\mathbf{5 A}-\mathbf{C}, \mathrm{n}=3-5)$.

\section{Effect of OBE on HDM-Induced Phosphorylation of ERK1/2 as Determined by Western Blotting}

In this experiment, we assessed the levels of p-ERK $1 / 2$ and total ERK1/2 by Western blotting in order to confirm and validate the immunofluorescence data. Western blotting analysis of lung homogenate (Figure 6A) confirmed the modulated levels of pERK1/2 as seen in the immunofluorescence. HDM challenge resulted in a marked increase in p-ERK1/2 levels compared to PBS-challenged mice (Figures 6A, B). Treatment with OBE resulted in a clear inhibition of the p-ERK1/2 and was similar to the dexamethasone-treated group (Figures $\mathbf{6 A}, \mathrm{B}, \mathrm{n}=3$ for each blot). The effect on HDM and OBE on total ERK1/2 was relatively unchanged.

\section{Effect of OBE on Airway Levels of Various Cytokines Using a Proteome Profiling- Based Technique}

The effect of OBE treatment $(60 \mathrm{mg} / \mathrm{kg})$ on the airway expression levels of various pro-inflammatory cytokines was determined. HDM challenge significantly enhanced the expression of the following interleukins (IL) by: IL-3 (147.4\%), IL-4 (104.6\%), IL-5 (5400\%), IL- 
10 (152.0\%), and tumor necrosis factor (TNF- $\alpha)(17,200 \%)(\mathrm{P}<$ 0.05; Figure 7A, $\mathrm{n}=4$ ) compared to PBS-challenged mice. Treatment with OBE significantly reduced the expression of all of the above molecules by approximately $98.2-99.5 \%$, except IL-10 (anti-inflammatory cytokine) which was significantly increased (78.6\%) above the HDM levels $(\mathrm{P}<0.05$; Figure 7A, $\mathrm{n}=4)$.

\section{Effect of OBE on Eosinophil Chemotaxis Ex Vivo}

In this experiment, eosinophils showed significant migration towards BAL fluid derived from HDM-challenged mice compared to BAL fluid from PBS-challenged mice $(16.5 \pm 2.4 \mathrm{vs}$ $4.2 \pm 0.6 \times 10^{4} / \mathrm{ml}, \mathrm{P}<0.05 ;$ Figure $\left.7 \mathrm{~B}\right)$. In contrast, pretreatment

A
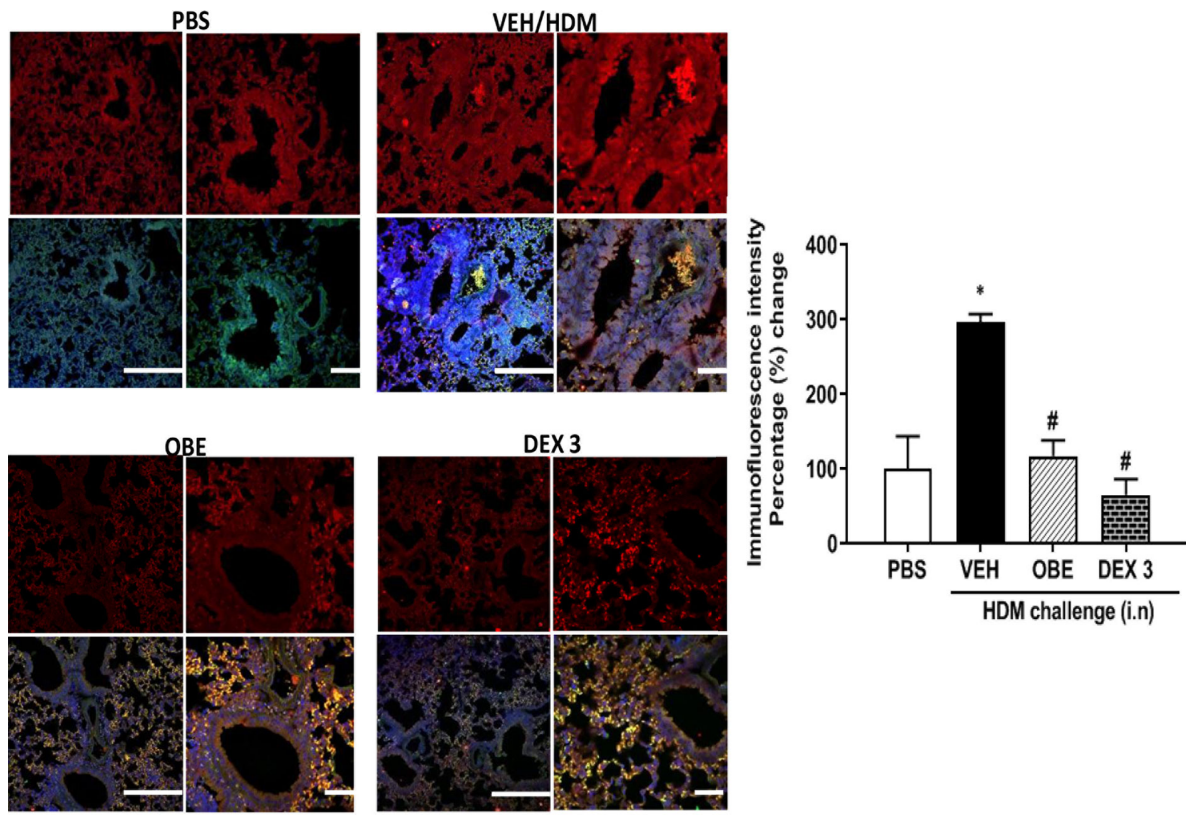

B
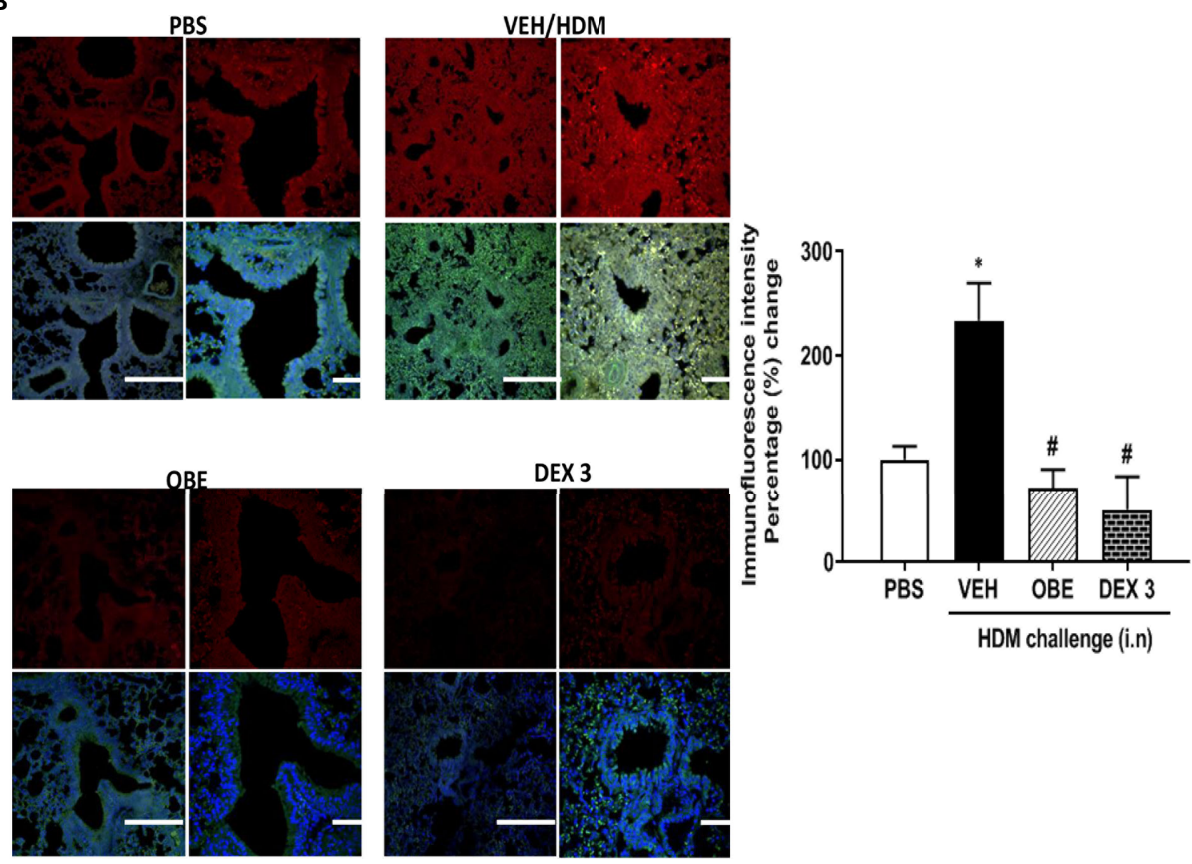

FIGURES 5 | Continued 


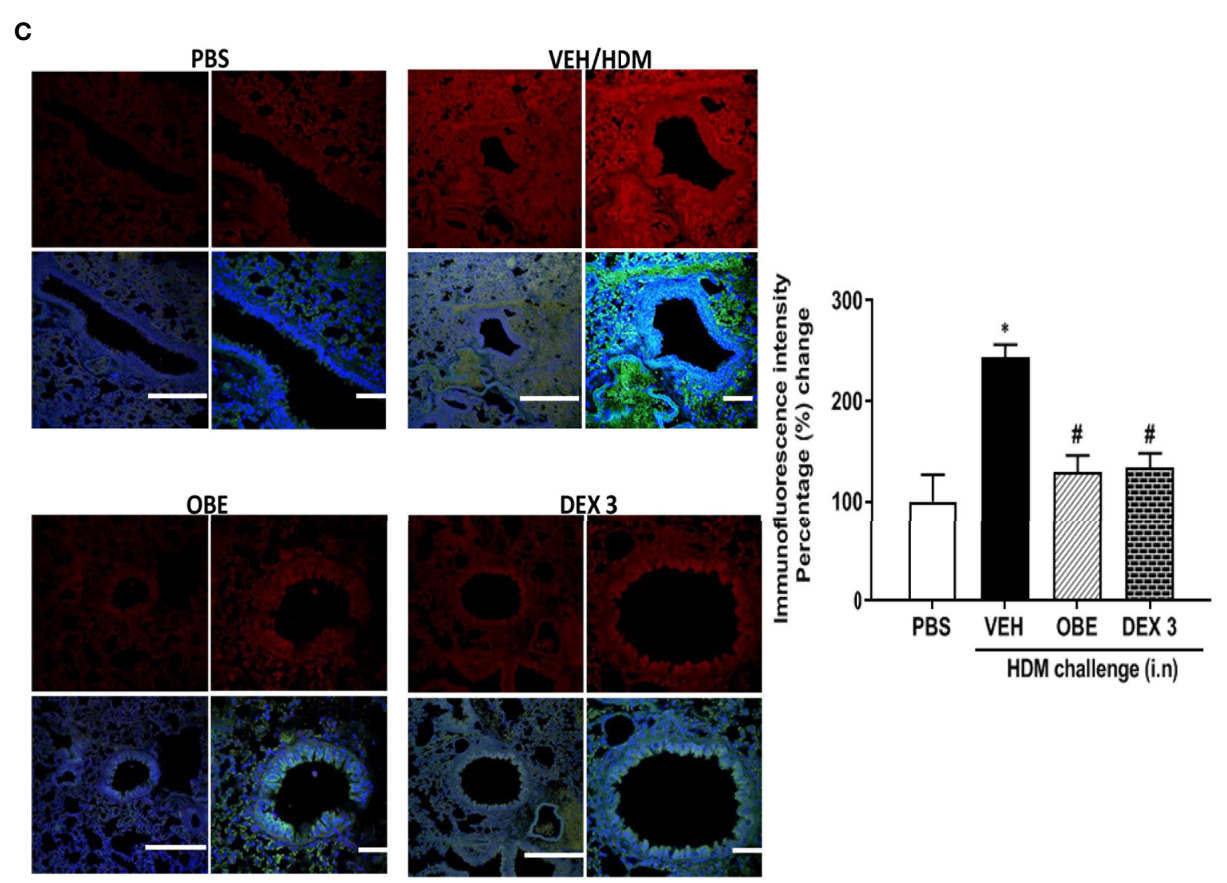

FIGURES 5 | Immunofluorescent (Alexa Fluor) detection of pEGFR (A) pERK1/2 (B) and pAKT (C) shown in the upper panels overlaid with DAPI stain on the lower panel to show lung tissue architecture. Lung sections were taken from different treatment groups: PBS-challenged mice (PBS), HDM-challenged mice pretreated with vehicle (HDM), HDM-challenged mice pretreated with OBE (60 mg/kg; i.p.) (OBE), and HDM-challenged mice pretreated with dexamethasone (DEX) and immunostained for pEGFR, pERK, and pAKT. PBS-treated mice showed minimal pEGFR, pERK1/2, and pAKT expression. HDM challenge resulted in a significant increase in pEGFR, pERK, and pAKT expression, and this was inhibited following treatment with OBE $(60 \mathrm{mg} / \mathrm{kg}$; i.p.) and was comparable to the dexamethasonetreated animals, scale bar $=50 \mu \mathrm{m}$. Graphs show quantitative assessment of fluorescence intensity of pEGFR, pERK1/2, and pAKT (arbitrary units). Data are expressed as mean \pm SEM $(n=3-5) .{ }^{*} P<0.05$ vs PBS group, ${ }^{*} \mathrm{P}<0.05$ vs HDM group.

A

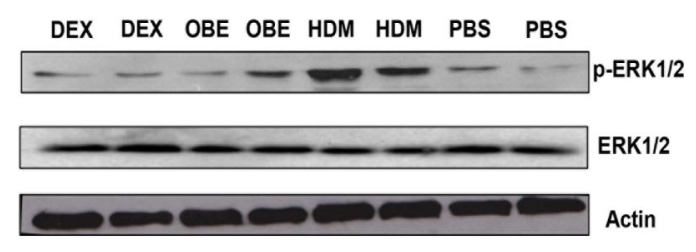

B

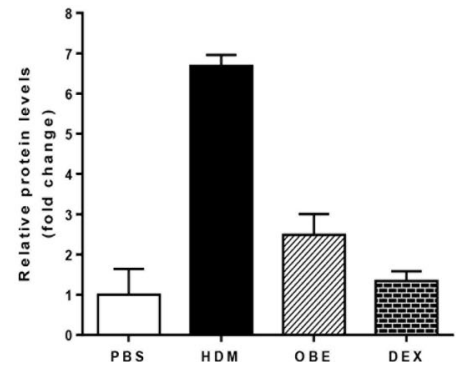

FIGURE 6 | (A) Western blot analysis of pERK1/2 and total ERK1/2 protein levels from lungs of PBS-challenged mice pretreated with vehicle (PBS), HDMchallenged mice pretreated with vehicle (HDM), HDM-challenged mice pretreated with OBE (60 mg/kg; i.p.) (OBE) and HDM-challenged mice pretreated with dexamethasone (DEX). The blots are of two pooled lung sample $(n=3$, for each). (B) Graph b shows relative densitometric quantification levels of $p E R K 1 / 2$ (relative to total ERK1/2, both normalized to $\beta$-actin).

with OBE (100 and 1,000 $\mathrm{ng} / \mathrm{ml})$ dose-dependently inhibited the HDM/BAL fluid-induced eosinophil chemotaxis $(6.4 \pm 1.0$ and 3.7 \pm 0.5 vs $16.5 \pm 2.4 \times 10^{4} / \mathrm{ml}$, respectively, $\mathrm{P}<0.05$; Figure $7 \mathbf{B}, \mathrm{n}=5$ ).

\section{Effect of OBE on HDM-Induced Airway Hyperresponsiveness}

In this experiment, we evaluated the effect of OBE treatment on the HDM-induced AHR ( $n=6-13)$. Our data show that there was a significant increase in airway responsiveness $24 \mathrm{~h}$ after the last intranasal HDM challenge as demonstrated by a significant increase in lung resistance $\left(\mathrm{R}_{\mathrm{L}}\right)$ to methacholine in the HDMchallenged mice as compared to the PBS-treated control mice at a dose of $25 \mathrm{mg} / \mathrm{ml}\left(5.2 \pm 0.2\right.$ vs $3.9 \pm 0.2 \mathrm{~cm} \mathrm{H}_{2} \mathrm{O}$ per ml/s) and $50 \mathrm{mg} / \mathrm{ml}\left(7.9 \pm 0.5\right.$ vs $4.6 \pm 0.3 \mathrm{~cm} \mathrm{H}_{2} \mathrm{O}$ per ml/s) (Figure 8; $\mathrm{P}<$ $0.05)$. However, treatment with $\mathrm{OBE}$ did not significantly reduce the average $\mathrm{R}_{\mathrm{L}}$ in comparison with the HDM-challenged/vehicle- 


$$
\text { A }
$$

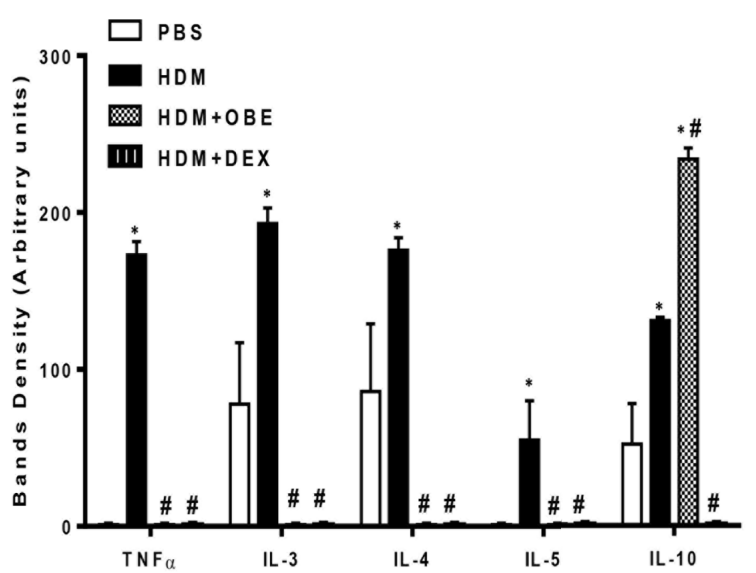

B

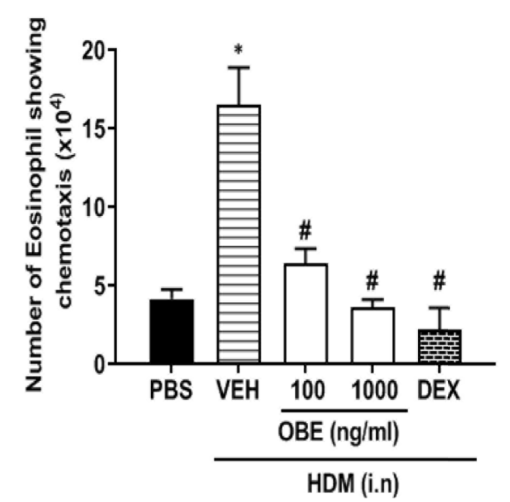

FIGURE 7 | (A) Effect of OBE treatment (60 mg/kg; i.p.) on the airway expression of various pro-inflammatory cytokines. HDM challenge significantly enhanced the expression of the following interleukins (IL): IL-3, IL-4, IL-5, IL-10, and tumor necrosis factor (TNF- $\alpha$ ). Treatment with OBE significantly reduced the expression of these cytokines except IL-10 which was significantly increased above the HDM levels. Data are expressed as mean \pm SEM $(n=4)$. *P $<0.05$ vs PBS group, " $\mathrm{P}<0.05$ vs HDM group. (B) Effect of OBE (100 and 1,000 ng/ml) on HDM/BALF-induced eosinophil chemotaxis. BALF from HDM-challenged mice induced a significant increase in eosinophil chemotaxis compared to BALF from PBS-challenged mice. Pretreatment with OBE (100 and 1,000 ng/ml) dosedependently inhibited eosinophil chemotaxis. Data are expressed as mean \pm SEM $(n=5) .{ }^{*} \mathrm{P}<0.05$ vs PBS group, ${ }^{\#} \mathrm{P}<0.05$ vs HDM group.

treated group at any of the tested doses of methacholine (Figure 8; $\mathrm{P}>0.05)$. Treatment with dexamethasone $(3 \mathrm{mg} / \mathrm{kg}$ ) nonetheless resulted in a significant reduction $(7.9 \pm 0.5$ vs $5.2 \pm$ $0.8 \mathrm{~cm} \mathrm{H}_{2} \mathrm{O}$ per ml/s) $(\mathrm{P}<0.05$; Figure 8) of the HDM-induced AHR at the $50 \mathrm{mg} / \mathrm{ml}$ of methacholine.

\section{Synergism Between OBE and Dexamethasone on Airway Inflammatory Cell Influx}

In this experiment, we evaluated the effect of combining OBE with dexamethasone on the HDM-induced total and differential cell influx. Treatment with either OBE $30 \mathrm{mg} / \mathrm{kg}$ or $0.5 \mathrm{mg} / \mathrm{kg}$ of dexamethasone had minimal to modest effects on the HDMinduced increase in the total cell count $(5.2 \pm 0.6$ and $4.3 \pm 0.2 \mathrm{vs}$ $6.4 \pm 0.5 \times 10^{5}$, respectively, Figure 9A, $\left.\mathrm{n}=7-11\right)$. Furthermore,

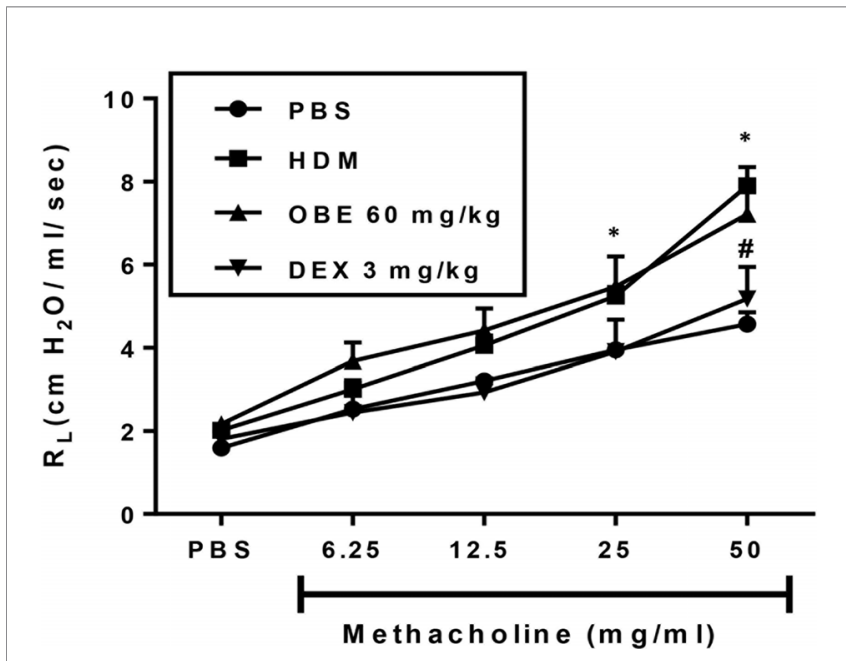

FIGURE 8 | Effect of OBE treatment on HDM-induced AHR to inhaled methacholine. HDM challenged mice demonstrated significant AHR compared to the control group at doses 25 and $50 \mathrm{mg} / \mathrm{kg}$ of methacholine. Treatment with dexamethasone (3 $\mathrm{mg} / \mathrm{kg}$; i.p.) significantly reduced the HDMinduced AHR. However, treatment with OBE (60 mg/kg; i.p.) did not significantly reduce the average $R_{L}$ in comparison with the HDM-challenged/ vehicle-treated group at any of the doses of methacholine tested $(P>0.05)$. Data are expressed as mean $\pm \operatorname{SEM}(n=6-13)$. ${ }^{*} \mathrm{P}<0.05$ vs PBS group, ${ }^{\#} \mathrm{P}<0.05$ for HDM group vs DEX group.

while treatment with either OBE at $30 \mathrm{mg} / \mathrm{kg}$ or dexamethasone at $0.5 \mathrm{mg} / \mathrm{kg}$ alone reduced the eosinophil influx, this did not reach statistical significance $(\mathrm{OBE} 30$ and $0.5 \mathrm{mg} / \mathrm{kg}$ dexamethasone alone $v s \mathrm{HDM}, 1.9 \pm 0.3$ and $1.3 \pm 0.1$ vs $3.7 \pm$ $0.3 \times 10^{5}$, respectively, $\mathrm{P}>0.05$; Figure $9 B$ ). However, when $\mathrm{OBE}$, at $30 \mathrm{mg} / \mathrm{kg}$, was combined with dexamethasone $[0.5 \mathrm{mg} / \mathrm{kg}]$, the inhibitory effect of this combination was significantly greater compared to either treatment when given alone $(2.7 \pm 0.2$ vs $5.2 \pm$ $0.6,4.3 \pm 0.2,6.4 \pm 0.5 \times 10^{5}$, respectively, $\mathrm{P}<0.05$, Figure 9A) and was indeed comparable to the high dose dexamethasone $(3 \mathrm{mg} / \mathrm{kg})$. Similarly, the combined treatment of both OBE $(30 \mathrm{mg} / \mathrm{kg})$ and dexamethasone $(0.5 \mathrm{mg} / \mathrm{kg})$, resulted in a significant reduction in the HDM-induced airways eosinophilia $(0.4 \pm 0.1$ vs $1.9 \pm 0.3,1.3 \pm 0.1$, $3.7 \pm 0.3 \times 10^{5}$, respectively, $\mathrm{P}<0.05$; Figure $\left.9 \mathrm{~B}\right)$ compared to either treament when given alone and was comparable to the high dose dexamethasone treatment $(3 \mathrm{mg} / \mathrm{kg})$.

\section{Synergism Between OBE and Dexamethasone on HDM-Induced Histopathological Changes}

In this experiment, our data show that treatment with either OBE $(30 \mathrm{mg} / \mathrm{kg})$ or dexamethasone $(0.5 \mathrm{mg} / \mathrm{kg})$ alone resulted in modest but significant reduction in the HDM-induced perivascular and peribronchial inflammation (cellular infiltration score; $3.5 \pm 0.2$ and $3.1 \pm 0.3$ vs $4.5 \pm 0.2$, respectively, $\mathrm{P}<0.05$; Figures $10 \mathrm{~A}, \mathbf{B}, \mathrm{n}=5$ ). However, when OBE $(30 \mathrm{mg} / \mathrm{kg})$ was combined with dexamethasone $(0.5 \mathrm{mg} /$ $\mathrm{kg}$ ), the inhibitory effect on the HDM-induced inflammation was now more marked and significantly greater than each treatment given alone (cellular infiltration score, $2.3 \pm 0.1$ vs $3.5 \pm 0.2,3.1 \pm$ 


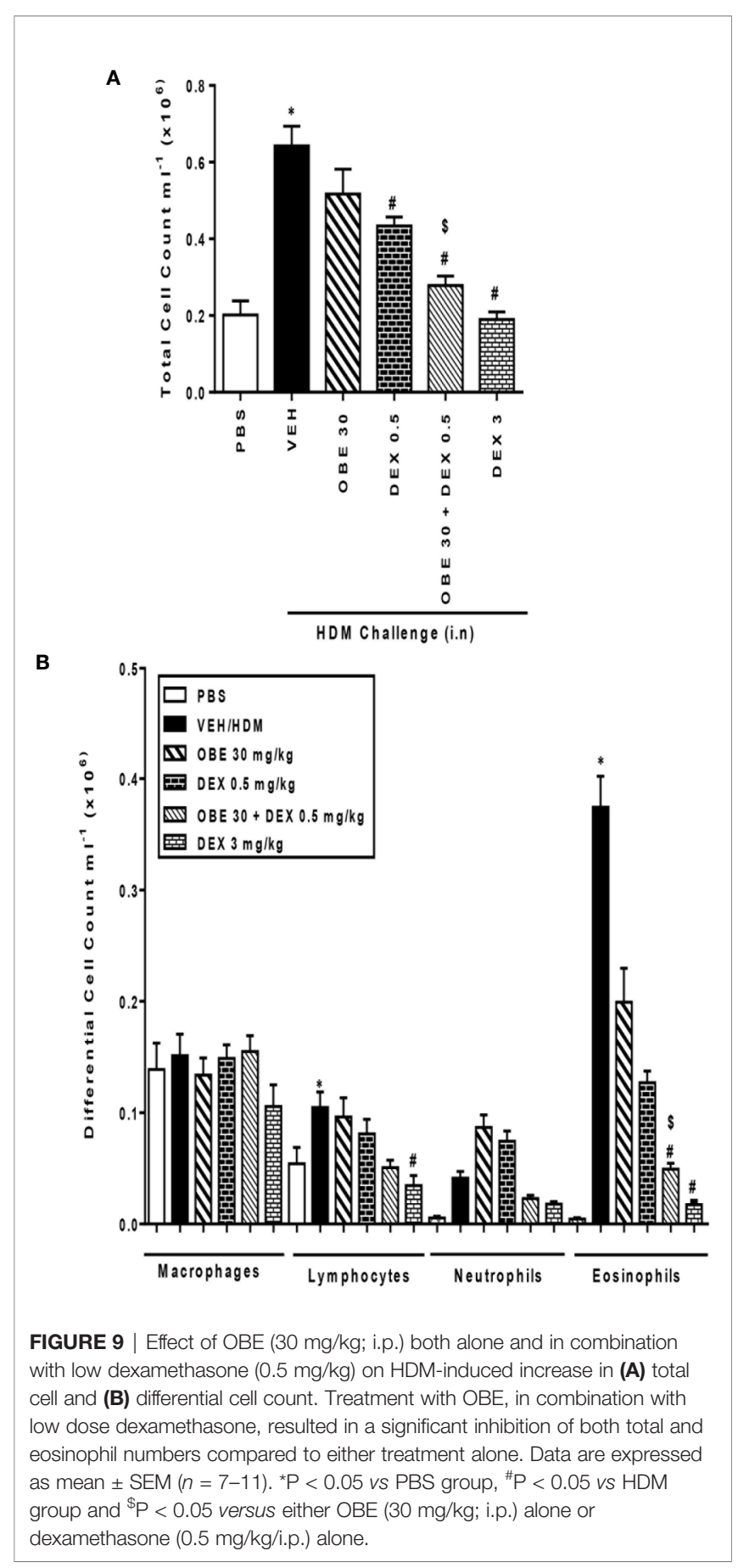

$0.3,4.5 \pm 0.2$, respectively, $\mathrm{P}<0.05$; Figures 10A, B) and was similar to the high dose dexamethasone $(3 \mathrm{mg} / \mathrm{kg})$ treatment. Similarly, treatment with either OBE $(30 \mathrm{mg} / \mathrm{kg})$ or dexamethasone $(0.5 \mathrm{mg} /$ $\mathrm{kg}$ ) alone resulted in a modest reduction in the HDM-induced goblet cell hyper/metaplasia and increase in bronchial mucus production (mucous intensity score; $3.5 \pm 0.2$ and $3.0 \pm 0.2$ vs 4.2 \pm 0.2 , respectively, $\mathrm{P}<0.05$; Figures $11 \mathrm{~A}, \mathbf{B}, \mathrm{n}=5$ ). However, the combination treatment of OBE $(30 \mathrm{mg} / \mathrm{kg})$ with dexamethasone (0.5 mg) significantly inhibited the HDM-induced goblet cell hyper/ metaplasia and increase in bronchial mucus production airway
A
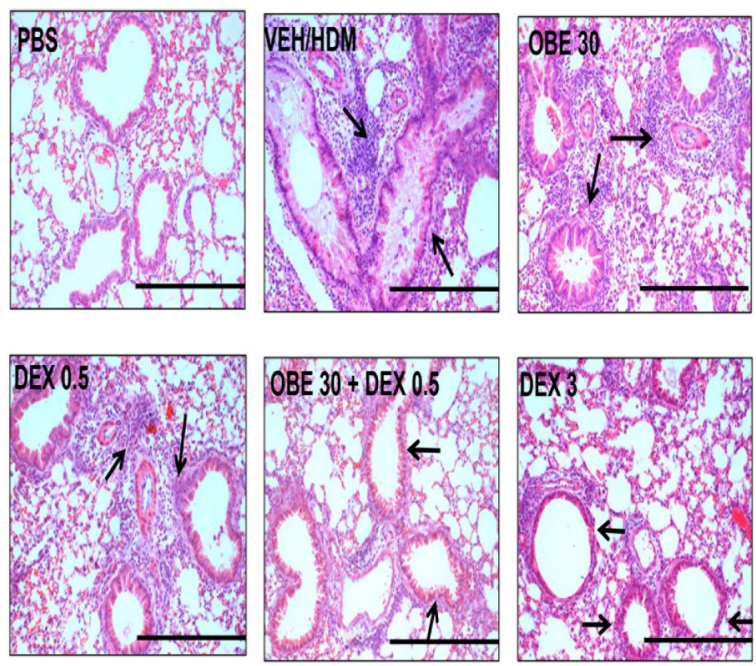

B

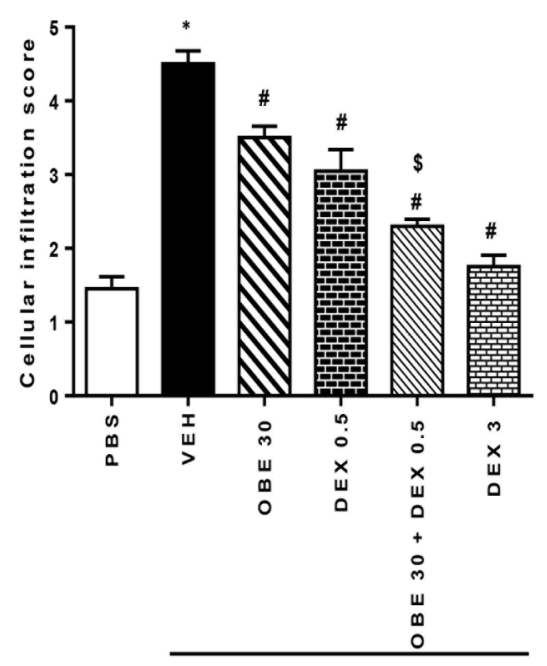

HDM challenge (i.n)

FIGURE 10 | Effect of OBE (30 mg/kg; i.p.) alone and in combination with low dexamethasone $(0.5 \mathrm{mg} / \mathrm{kg})$ on HDM-induced peribronchial and perivascular inflammatory cell infiltrations. (A) Representative lowmagnification light photomicrographs displaying H\&E staining of whole lung samples from control PBS-challenged mice (PBS), HDM-challenged mice (HDM), HDM-challenged mice pretreated with OBE (30 mg/kg; i.p.) (OBE 30), HDM-challenged mice pretreated with low dexamethasone treated $(0.5 \mathrm{mg} /$ kg; i.p.) (DEX 0.5), HDM-challenged mice pretreated with a combination of OBE (30 mg/kg; i.p.) and low dexamethasone treated (0.5 mg/kg; i.p.) (DEX 30 + DEX 0.5), HDM-challenged mice pretreated with high dose dexamethasone (3 mg/kg; i.p.) (DEX 3), scale bar = $200 \mu \mathrm{m}$. Graphs shows (B) cellular infiltration score for H\&E. OBE treatment in combination with low dose dexamethasone resulted in a significant decrease in both peribronchial and perivascular inflammatory compared to either treatment when give alone. Data are expressed as mean \pm SEM $(n=5)$. ${ }^{*} \mathrm{P}<0.05$ vs PBS, ${ }^{\#} \mathrm{P}<0.05$ vs HDM and ${ }^{\$} \mathrm{P}<0.05$ versus either OBE (30 mg/ $/ \mathrm{kg}$; i.p.) alone group or dexamethasone $(0.5 \mathrm{mg} / \mathrm{kg} / \mathrm{i} . \mathrm{p}$.$) alone group.$

when compared to either OBE $(30 \mathrm{mg} / \mathrm{kg})$ or dexamethasone $(0.5$ $\mathrm{mg} / \mathrm{kg}$ ) given alone (mucous intensity score; $2.2 \pm 0.4$ vs $3.5 \pm 0.2$, $3.0 \pm 0.2,4.2 \pm 0.2$, respectively, $\mathrm{P}<0.05$; Figures $11 \mathrm{~A}, \mathbf{B})$ and was almost as effective as dexamethasone at $3 \mathrm{mg} / \mathrm{kg}$. 
A
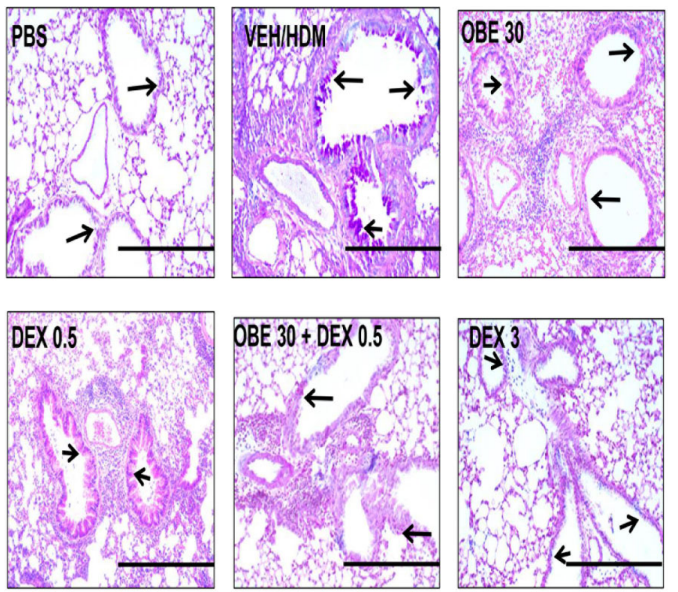

B

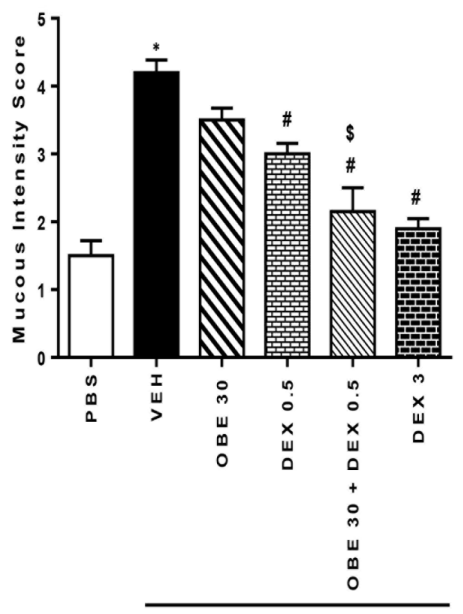

HDM challenge (i.n)

FIGURE 11 | Effect of OBE (30 mg/kg; i.p.) both alone and in combination with low dexamethasone $(0.5 \mathrm{mg} / \mathrm{kg})$ on HDM-induced bronchial mucous production and goblet cell hyper/metaplasia. (A) Representative lowmagnification light photomicrographs displaying PAS staining of whole lung samples from control PBS-challenged mice (PBS), HDM-challenged mice (HDM), HDM-challenged mice pretreated with OBE (30 mg/kg; i.p.) (OBE 30), HDM-challenged mice pretreated with low dose dexamethasone $(0.5 \mathrm{mg} / \mathrm{kg}$; i.p.) (DEX 0.5), HDM-challenged mice pretreated with a combination of OBE (30 mg/kg; i.p.) and low dose dexamethasone ( $0.5 \mathrm{mg} / \mathrm{kg}$; i.p.) (OBE 30 + DEX 0.5), HDM-challenged mice pretreated with high dose dexamethasone (3 mg/kg; i.p.) (DEX 3), scale bar $=200 \mu m$. Graphs show (B) mucous intensity score. OBE treatment in combination with low dose dexamethasone resulted in a significant decrease in bronchial mucus production and goblet cell hyper/ metaplasia compared to either treatment when give alone. Data are expressed as mean \pm SEM $(n=5)$. ${ }^{*} \mathrm{P}<0.05$ vs PBS and ${ }^{\#} \mathrm{P}<0.05$ vs HDM and ${ }^{\$} \mathrm{P}<0.05$ versus either $\mathrm{OBE}(30 \mathrm{mg} / \mathrm{kg}$; i.p.) alone group or dexamethasone (0.5 mg/kg/i.p.) alone group.

\section{Synergism Between OBE and Dexamethasone on HDM-Induced pERK1/ 2 Levels}

In this experiment, our data show that treatment with either OBE $(30 \mathrm{mg} / \mathrm{kg})$ or the low dose dexamethasone $(0.5 \mathrm{mg} / \mathrm{kg})$ did not result in marked inhibition of the HDM-induced phosphorylation of ERK1/2 (267.0 \pm 13.8 and $264.8 \pm 4.9$ vs $319.0 \pm 10.4 \%$, respectively, $\mathrm{P}<0.05$; Figure 12, $\mathrm{n}=4-5)$. However, when OBE $(30 \mathrm{mg} / \mathrm{kg})$ was combined with the low dexamethasone $(0.5 \mathrm{mg} / \mathrm{kg})$, there was now a marked and significant reduction in pERK1/2 levels compared to either OBE $(30 \mathrm{mg} / \mathrm{kg}$ ) or the low dose dexamethasone $(0.5 \mathrm{mg} / \mathrm{kg})$ alone $(80.0 \pm 16.0$ vs $267.0 \pm 13.8$ and $264.8 \pm 4.9$, respectively, $\mathrm{P}<0.05$; Figure 12). Of interest, the degree of inhibitory effect on pERK1/2, in the combination treatment, was twofold greater than that were obtained with the high dexamethasone dose $(3 \mathrm{mg} / \mathrm{kg})(\mathrm{P}<0.05$; Figure 12).

\section{DISCUSSION}

The major finding of this study is that OBE produces antiinflammatory actions in an established asthma model, partly, via inhibition of the EGFR/ERK1/2/AKT pathway. Furthermore, our data show that combined treatment with OBE and a classical steroid (dexamethasone) at sub-maximal doses resulted in an enhanced anti-inflammatory effect at the cellular, histopathological, and molecular levels.

The use of natural products as therapeutic agents has been on the rise, not only due to their demonstrated efficacy (both in humans and in preclinical models of disease) but possibly due to their perceived, and in many instances, real lack of adverse effects, even when consumed in large quantities (Bohlin et al., 2010; Atanasov et al., 2015). Based on this, many studies have been conducted over the past decades in an attempt to understand the scientific basis for the use of many natural products, elucidate their actions, and identify their mechanisms of action in animal models of disease (Fang et al., 2017). To this point, several studies have reported that OBE, or its constituents, have many pharmacological actions in many conditions and diseases such as wounds, scars, dysentery, inflammation, hypertension, and also asthma.

Our data show that OBE dose-dependently decreased the total and differential cell influx into the airways, at both 60 and $100 \mathrm{mg} / \mathrm{kg}$ dose, confirming data from recent studies reporting its inhibitory effect on BAL fluid cellularity (Ghorani et al., 2018). In line with this, we found that $60 \mathrm{mg} / \mathrm{kg}$ dose of OBE resulted in significant reduction of the HDM-induced perivascular and peribronchial inflammatory cell infiltration and goblet cell hyper/metaplasia. These anti-inflammatory actions were comparable to the action of dexamethasone $(3 \mathrm{mg} / \mathrm{kg})$ which indicates that the anti-inflammatory action of OBE is, at least, as effective as that of steroids. Our findings are in agreement with studies showing anti-inflammatory action of OBE in asthma-like models and more recently in a mouse model of colitis (Ghorani et al., 2018; Khajah et al., 2019). It is of interest to note that many of the documented activities for onion extract have been attributed to its polar constituents, particularly the known flavonoid quercetin, where polar solvents were mainly used to prepare the tested extracts (Oliveira et al., 2015). However, in this study, the anti-inflammatory action noted are most likely due to non-polar fat-soluble constituents, such as sulfur-containing compounds, mainly dipropyl disulfide and dipropyl trisulfide, which were found in abundance in the essential oil of onion since dichloromethane was used for the extraction method. 

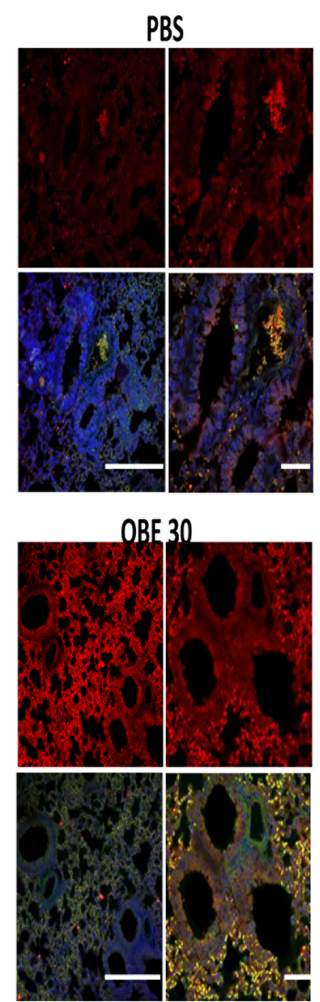

OBE $30+D E X 0.5$
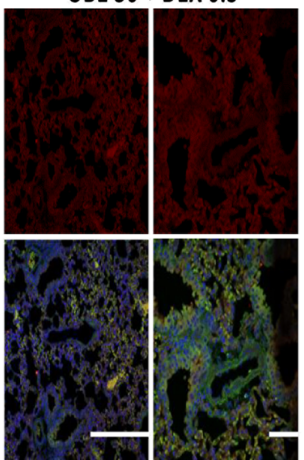

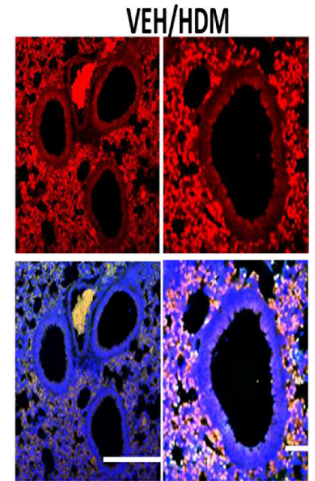

DEX 0.5

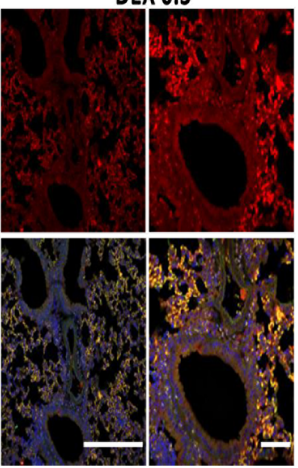

DEX3

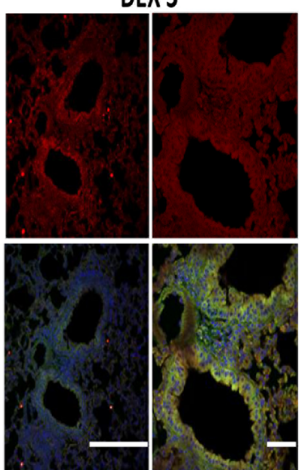

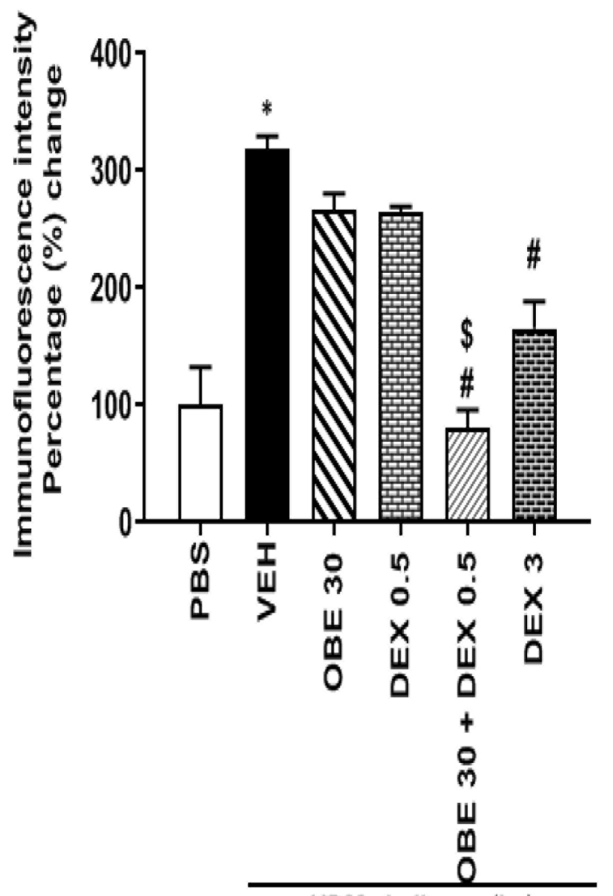

HDM challenge (i.n)

FIGURE 12 | Immunofluorescence (Alexa Fluor) detection of phosphorylated ERK1/2 are shown in the upper panels overlaid with DAPI stain on the lower panel to show lung tissue architecture. Lung sections were taken from different treatment groups, control PBS-challenged mice (PBS), HDM-challenged mice (HDM), HDMchallenged mice pretreated with OBE (30 mg/kg; i.p.) (OBE 30), HDM-challenged mice pretreated with low dose dexamethasone (0.5 mg/kg; i.p.) (DEX 0.5), HDMchallenged mice pretreated with a combination of OBE (30 mg/kg; i.p.) and low dose dexamethasone (0.5 mg/kg; i.p.) (OBE 30 + DEX 0.5), HDM-challenged mice pretreated with high dose dexamethasone (3 mg/kg; i.p.) (DEX 3), scale bar $=50 \mu \mathrm{m}$. Graph shows quantitative assessment of fluorescence intensity of ERK (arbitrary units). Data are expressed as mean \pm SEM $(n=4-5)$. ${ }^{*} \mathrm{P}<0.05$ vs PBS and ${ }^{\#} \mathrm{P}<0.05$ vs HDM and ${ }^{\$} \mathrm{P}<0.05$ versus either OBE (30 mg/kg; i.p.) alone group or dexamethasone (0.5 mg/kg/i.p.) alone group.

The EGF/EGFR is a critical signaling pathway in the pathogenesis of asthma, and both EGF and EGFR levels have been shown to be consistently increased in both human asthma and in animal models of asthma (Amishima et al., 1998; Puddicombe et al., 2000; Song L. et al., 2016). However, other ligands such as heparin-binding EGF-like growth factor (HBEGF), amphiregulin, and betacellulin can also bind to and activate EGFR (Acciani et al., 2016; Ha and Rogers, 2016). In addition, ERK1/2 and AKT are not only key signaling molecules in asthma but have also been recently shown to be downstream of EGFR activation (El-Hashim et al., 2017). Our data show that treatment with OBE not only inhibited the development of asthma but also reduced pEGFR levels. Of interest and relevance is data from a recent study from our group, and that of others, using a similar model of asthma, has shown that treatment with selective EGFR inhibitors inhibited the EGFR- 
dependent signaling pathway and also reduced eosinophil recruitment, airway inflammation, AHR, and goblet cell hyper/ metaplasia (Song L. et al., 2016; El-Hashim, 2017). Therefore, our findings would imply that the inhibitory effects of OBE on the asthmatic phenotype may be, at least partly, via inhibition of EGFR-dependent signaling perturbation. However, it is also likely that in addition to the EGFR pathway, OBE may inhibit other pro-inflammatory signaling pathways.

Our data also show that HDM-induced increase in pERK1/2 and pAKT were both inhibited following OBE treatment. While it is plausible that the effect of $\mathrm{OBE}$ on these signaling molecules represents independent and separate effects, since both ERK1/2 and $\mathrm{AKT}$ are ubiquitous signaling molecules, we have previously reported that AG1478, a selective EGFR receptor inhibitor, inhibited not only EGFR activation but also decreased pERK1/ 2 and pAKT levels, suggesting that both molecules are downstream of EGFR activation (El-Hashim et al., 2017). Therefore, it is very likely that the inhibitory effect of OBE on these two molecules is primarily due to upstream inhibition of EGFR-dependent signaling. This notion is further confirmed by our recent study showing that the effects of the antiinflammatory endogenous molecule, Ang-(1-7), in asthma, are mediated via inhibition of the EGFR/ERK1/2 dependent signaling (El-Hashim et al., 2019). That OBE can inhibit the EGFR-triggered signaling perturbations suggests that it can inhibit a central signaling pathway in asthma.

It is well recognized that asthma is an immune response driven by Th2 and Th17 cells with cytokines such as IL-4, IL-5, IL-9, IL-10, IL-13, and IL-7 playing important roles (Saeki et al., 2019). Moreover, Th1 cytokines such as TNF- $\alpha$ and IFN- $\gamma$ are also involved in asthma, with pro - and anti-asthma effects, respectively. Our findings show that $\mathrm{OBE}$ treatment resulted in a significant reduction of IL- 4 and IL- 5 consistent with other studies and effects of drugs that mediate an anti-allergic/anti-asthma action (Seo et al., 2019). In addition, OBE treatment decreased the proasthma TNF- $\alpha$ but increased the Th 2 anti-inflammatory cytokine, IL-10. It is therefore plausible that the OBE-induced increase in IL10 levels may, in part, explain the anti-inflammatory action of OBE in general and/or the specific decrease in the levels of IL- 4 and IL-5, as these cytokines are known to have a reciprocal relationship (Oliveira et al., 2015).

The recent introduction of monoclonal antibodies targeting the eosinophil chemoattractant underscores the importance of eosinophils in asthma (Agache et al., 2020). Our data show that treatment with $\mathrm{OBE}$ significantly reduced eosinophil numbers not only in the tissue but also their ex vivo chemotaxis towards BAL fluid from HDM challenged mice. Studies have shown that onion constituents, such as thiosulfinates and cepaenes, dose-dependently inhibit both cyclooxygenase and 5-lipoxygenase enzyme activity (Werz, 2007). Furthermore, products of 5-lipoxygenase, namely the cysteinyl leukotrienes $\mathrm{LTC}_{4}, \mathrm{LTD}_{4}$, and $\mathrm{LTE}_{4}$, are known to be potent inducers of eosinophil chemotaxis (Werz, 2007). Therefore, inhibition of 5-lipoxygenase may represent one possible mechanism by which OBE inhibits eosinophil chemotaxis.

Our data also show that HDM challenge resulted in the induction of AHR, a characteristic feature of both clinical and preclinical asthma that is not easily amenable to asthma therapy (Busse, 2010; Ezeamuzie et al., 2014). Our findings show that treatment with OBE had no effect on this parameter. Although many studies have reported a causal link between airway inflammation and AHR, others have not been able to confirm this relationship, at least not for all types of AHR (Gozzard et al., 1996; Spina et al., 1998; El-Hashim et al., 1999; Spina and Page, 2009). Indeed, there may be a separation between the two phenomena, as not all agents that inhibit airway inflammation reduce AHR and vice versa (Riccio et al., 1997; El-Hashim et al., 2004). Recent studies have also provided good evidence that airway sensory hyper-excitability may also underlie AHR, and hyperactivity of airway nerves is less susceptible to antiinflammatory agents (Spina and Page, 2009; Delescluse et al., 2012; Lommatzsch, 2012).

Although ICS have been the mainstay treatment for asthma, being effective anti-inflammatory agents, their major limitation is their high side effect profile, particularly with moderate-tohigh doses (Hossny et al., 2016). In addition, the high cost of ICS is a real problem in poorer regions of the world (Watson and Lewis, 1997). To test whether OBE and steroids have a synergistic effect, we combined a low dose of OBE, $30 \mathrm{mg} / \mathrm{kg}$ and a low dose of dexamethasone, $0.5 \mathrm{mg} / \mathrm{kg}$ both of which produced minimal to mild anti-inflammatory effect when given alone. An important and novel finding in this study is that when OBE is combined with a low dose dexamethasone, a more powerful and effective anti-inflammatory effect was produced. Our data also show that the combination treatment resulted in a marked and significant enhancement of the anti-inflammatory effects on the total cell, eosinophil influx, histopathological changes (both perivascular and peribronchial inflammation and goblet cell hyper/ metaplasia) when compared to either treatment alone. This combination was at least as effective as the high dose $(3 \mathrm{mg} /$ $\mathrm{kg}$ ) steroid. To determine whether this was being mediated via enhanced suppression of the EGFR/ERK1/2/AKT signaling pathway, we assessed p-ERK1/2 expression level as a marker of activation of this signaling pathway. Our results clearly show that whilst neither $0.5 \mathrm{mg} / \mathrm{kg}$ dexamethasone nor $30 \mathrm{mg} / \mathrm{kg}$ alone had any effect on p-ERK1/2 levels, when both agents are combined, a significant and dramatic decrease in p-ERK1/2 levels was detected. This clearly indicates that the enhanced suppressive effects are being mediated via synergistic actions at the molecular level.

In conclusion, our data clearly show that OBE inhibits the asthma phenotype in a clinically relevant murine model of asthma, at least in part, via inhibition of Th2 cytokine profile, via inhibition of the EGFR/ERK/1/2/AKT signaling pathway. In addition, our data also show that combining OBE with steroids resulted in an enhanced anti-inflammatory effect via a synergistic action at the molecular signaling level. Therefore, this study not only identifies an important molecular signaling pathway that is targeted by OBE to inhibit the asthma phenotype, but also shows that $\mathrm{OBE}$ synergizes with steroids resulting in a greater antiinflammatory action. This finding may have important implication for the treatment of asthma as it provides a potential to reduce steroid toxicity while maintaining efficacy. 


\section{DATA AVAILABILITY STATEMENT}

The raw data supporting the conclusions of this article will be made available by the authors, without undue reservation.

\section{ETHICS STATEMENT}

The animal study was reviewed and approved by Animal Welfare and Use of Laboratory Animals Committee in the Health Sciences Center.

\section{AUTHOR CONTRIBUTIONS}

Conceived and designed the experiments: $\mathrm{AE}-\mathrm{H}, \mathrm{MK}$, and $\mathrm{KO}$. Performed the experiments: SB, AA and HS. Analyzed the data: $\mathrm{SB}, \mathrm{AA}, \mathrm{HS}, \mathrm{AE}-\mathrm{H}, \mathrm{KO}$, and MK. Wrote the paper: AE-H. Edited the paper: $\mathrm{KO}$ and $\mathrm{MK}$. All authors contributed to the article and approved the submitted version.

\section{REFERENCES}

Abdel-Lateef, E., Rabia, I., Abdel-Gawad, M., and El-Sayed, M. (2018). In vitro antischistosomal activity of Allium cepa L. (red onion) extracts and identification of the essential oil composition by GC-MS. J. Microbiol. Biotechnol. Food Sci. 7, 421-425. doi: 10.15414/jmbfs.2018.7.4.421-425

Acciani, T. H., Suzuki, T., Trapnell, B. C., and Le Cras, T. D. (2016). Epidermal growth factor receptor signalling regulates granulocyte-macrophage colonystimulating factor production by airway epithelial cells and established allergic airway disease. Clin. Exp. Allergy 46 (2), 317-328. doi: 10.1111/cea.12612

Agache, I., Beltran, J., Akdis, C., Akdis, M., Canelo-Aybar, C., Canonica, W., et al. (2020). Efficacy and safety of treatment with biologicals (benralizumab, dupilumab, mepolizumab, omalizumab and reslizumab) for severe eosinophilic asthma. Allergy 75 (5), 1023-1042. doi: 10.1111/all.14221

Amishima, M., Munakata, M., Nasuhara, Y., Sato, A., Takahashi, T., Homma, Y., et al. (1998). Expression of epidermal growth factor and epidermal growth factor receptor immunoreactivity in the asthmatic human airway. Am. J. Respir. Crit. Care Med. 157 (6 Pt 1), 1907-1912. doi: 10.1164/ajrccm.157.6.9609040

Atanasov, A. G., Waltenberger, B., Pferschy-Wenzig, E. M., Linder, T., Wawrosch, C., Uhrin, P., et al. (2015). Discovery and resupply of pharmacologically active plant-derived natural products: a review. Biotechnol. Adv. 33 (8), 1582-1614. doi: 10.1016/j.biotechadv.2015.08.001

Athari, S. S. (2019). Targeting cell signaling in allergic asthma. Signal Transduct. Target Ther. 4, 45. doi: 10.1038/s41392-019-0079-0

Aun, M. V., Bonamichi-Santos, R., Arantes-Costa, F. M., Kalil, J., and GiavinaBianchi, P. (2017). Animal models of asthma: utility and limitations. J. Asthma Allergy 10, 293-301. doi: 10.2147/JAA.S121092

Beasley, R., Harper, J., Bird, G., Maijers, I., Weatherall, M., and Pavord, I. D. (2019). Inhaled corticosteroid therapy in adult asthma. Time for a new therapeutic dose terminology. Am. J. Respirat. Crit. Care Med. 199 (12), 1471-1477. doi: 10.1164/rccm.201810-1868CI

Bohlin, L., Göransson, U., Alsmark, C., Wedén, C., and Backlund, A. (2010). Natural products in modern life science. Phytochem. Rev. 9 (2), 279-301. doi: 10.1007/s11101-009-9160-6

Brown, A., Elmhirst, E., and Gardner, J. (2017). EP Vantage 2018 Preview. (Evaluate Ltd.), 1-26.

Burgel, P. R., Montani, D., Danel, C., Dusser, D. J., and Nadel, J. A. (2007). A morphometric study of mucins and small airway plugging in cystic fibrosis. Thorax 62 (2), 153-161. doi: 10.1136/thx.2006.062190

Busse, W. W. (2010). The relationship of airway hyperresponsiveness and airway inflammation: airway hyperresponsiveness in asthma: its measurement and clinical significance. Chest 138 (2 Suppl), 4S-10S. doi: 10.1378/chest.10-0100

\section{FUNDING}

This work was supported by Kuwait Foundation for the Advancement of Sciences, grant number: P11613PT01. Parts of this work were supported by grant SRUL02/13 to the Research Unit for Genomics, Proteomics and Cellomics Studies (OMICS), Kuwait University. GC-MS analyses were done at Research Sector Project Unit (RSPU), Faculty of Science, Kuwait University, supported by Grant numbers GS01/03.

\section{ACKNOWLEDGMENTS}

The authors are thankful for the support of Mr. Sunny Ojoko and Mr. Hecktor Velasco from the Animal Resources Center of Health Sciences Center. The authors would also like to thank Mr. Yousef Al-Farahan, Ms Sahar Farag, and Prof Waleed Renno for the early work done with the ovalbumin asthma model. We would also like to thank Prof Samuel Kombian for discussion and proofreading the manuscript.

Carr, T. F., and Kraft, M. (2017). Management of severe asthma before referral to the severe asthma specialist. J. Allergy Clin. Immunol. Pract. 5 (4), 877-886. doi: 10.1016/j.jaip.2017.04.027

Clark, C. E., Arnold, E., Lasserson, T. J., and Wu, T. X. (2010). Herbal interventions for chronic asthma in adults and children: a systematic review and meta-analysis. Primary Care Respirat. J. 19 (4), 307-314. doi: 10.4104/ pcrj.2010.00041

Correa, M. F., Barbosa, A. J. R., Teixeira, L. B., Duarte, D. A., Simoes, S. C., Parreiras, E. S. L. T., et al. (2017). Pharmacological Characterization of 5Substituted 1-[(2,3-dihydro-1-benzofuran-2-yl)methyl]piperazines: novel antagonists for the histamine $\mathrm{H} 3$ and $\mathrm{H} 4$ receptors with antiinflammatory potential. Front. Pharmacol. 8, 825. doi: 10.3389/fphar. 2017.00825

de Boer, W. I., Hau, C. M., van Schadewijk, A., Stolk, J., van Krieken, J. H. J., and Hiemstra, P. S. (2006). Expression of epidermal growth factors and their receptors in the bronchial epithelium of subjects with chronic obstructive pulmonary disease. Am. J. Clin. Pathol. 125 (2), 184-192. doi: 10.1309/ W1AXKGT7UA37X257

Delescluse, I., Mace, H., and Adcock, J. (2012). Inhibition of airway hyperresponsiveness by TRPV1 antagonists (SB-705498 and PF-04065463) in the unanaesthetized, ovalbumin-sensitized guinea pig. Br. J. Pharmacol. 166 (6), 1822-1832. doi: 10.1111/j.1476-5381.2012.01891.x

Dorsch, W., Schneider, E., Bayer, T., Breu, W., and Wagner, H. (1990). Antiinflammatory effects of onions: inhibition of chemotaxis of human polymorphonuclear leukocytes by thiosulfinates and cepaenes. Int. Arch. Allergy Appl. Immunol. 92 (1), 39-42. doi: 10.1159/000235221

El-Hashim, A. Z., Banner, K. H., Paul, W., and Page, C. P. (1999). Effects of dexamethasone on airway hyper-responsiveness to the adenosine A1 receptor agonist cyclo-pentyl adenosine in an allergic rabbit model. $\mathrm{Br}$. J. Pharmacol. 126 (6), 1513-1521. doi: 10.1038/sj.bjp.0702455

El-Hashim, A. Z., Buchheit, K. H., Fozard, J., and Page, C. (2004). Effect of the K+(ATP) channel opener, KCO912, on baseline and allergen induced airway hyperresponsiveness in allergic rabbits. Eur. J. Pharmacol. 484 (2-3), 351-356. doi: 10.1016/j.ejphar.2003.11.018

El-Hashim, A. Z., Khajah, M. A., Renno, W. M., Babyson, R. S., Uddin, M., Benter, I. F., et al. (2017). Src-dependent EGFR transactivation regulates lung inflammation via downstream signaling involving ERK1/2, PI3Kdelta/Akt and NFkappaB induction in a murine asthma model. Sci. Rep. 7 (1), 9919. doi: 10.1038/s41598-017-09349-0

El-Hashim, A. Z., Khajah, M. A., Babyson, R. S., Renno, W. M., Ezeamuzie, C. I., Benter, I. F., et al. (2019). Ang-(1-7)/ MAS1 receptor axis inhibits allergic airway inflammation via blockade of Src-mediated EGFR transactivation in a 
murine model of asthma. PLoS One 14 (11), e0224163. doi: 10.1371/ journal.pone. 0224163

Ezeamuzie, C.II, El-Hashim, A. Z., Renno, W. M., and Edafiogho, I. O. (2014). Antiallergic and antiasthmatic effects of a novel enhydrazinone ester (CEE-1): inhibition of activation of both mast cells and eosinophils. J. Pharmacol. Exp. Ther. 350 (2), 444-454. doi: 10.1124/jpet.114.213751

Fang, J., Gao, L., Ma, H., Wu, Q., Wu, T., Wu, J., et al. (2017). Quantitative and systems pharmacology 3. network-based identification of new targets for natural products enables potential uses in aging-associated disorders. Front. Pharmacol. 8, 747. doi: 10.3389/fphar.2017.00747

Fredotovic, Z., Soldo, B., Sprung, M., Marijanovic, Z., Jerkovic, I., and Puizina, J. (2020). Comparison of organosulfur and amino acid composition between triploid onion Allium Cornutum Clementi ex Visiani 1842, and common onion Allium cepa L., and evidences for antiproliferative activity of their extracts. Plants (Basel) 9 (1), 98. doi: 10.3390/plants9010098

Ghorani, V., Marefati, N., Shakeri, F., Rezaee, R., Boskabady, M., and Boskabady, M. H. (2018). The effects of Allium cepa extract on tracheal responsiveness, lung inflammatory cells and phospholipase A2 level in asthmatic rats. Iranian J. Allergy Asthma Immunol. 17 (3), 221-231.

GINA (2019). Global initiative for asthma (GINA): Global strategy for asthma management and prevention. (Global Initiative for Asthma). Available at: http://www.ginasthma.or (Retrieved January 26, 2020).

Gitin, L., Dinica, R., Neagu, C., and Dumitrascu, L. (2014). Sulfur compounds identification and quantification from Allium spp. fresh leaves. J. Food Drug Anal. 22 (4), 425-430. doi: 10.1016/j.jfda.2014.04.002

Gomez-Cambronero, J., Horn, J., Paul, C. C., and Baumann, M. A. (2003). Granulocyte-macrophage colony-stimulating factor is a chemoattractant cytokine for human neutrophils: involvement of the ribosomal p70 S6 kinase signaling pathway. J. Immunol. 171 (12), 6846-6855. doi: 10.4049/ jimmunol.171.12.6846

Gorska, M. M. (2018). Mouse models of asthma. Methods Mol. Biol. 1809, 351362. doi: 10.1007/978-1-4939-8570-8_23

Gozzard, N., el-Hashim, A. , Herd, C. M., Blake, S. M., Holbrook, M., Hughes, B., et al. (1996). Effect of the glucocorticosteroid budesonide and a novel phosphodiesterase type 4 inhibitor CDP840 on antigen-induced airway responses in neonatally immunised rabbits. Br. J. Pharmacol. 118 (5), 12011208. doi: $10.1111 /$ j.1476-5381.1996.tb15524.x

Ha, E. V. S., and Rogers, D. F. (2016). Novel therapies to inhibit mucus synthesis and secretion in airway hypersecretory diseases. Pharmacology 97 (1-2), 84100. doi: $10.1159 / 000442794$

Hansel, T. T., De Vries, I. J., Iff, T., Rihs, S., Wandzilak, M., Betz, S., et al. (1991). An improved immunomagnetic procedure for the isolation of highly purified human blood eosinophils. J. Immunol. Methods 145 (1-2), 105-110. doi: 10.1016/0022-1759(91)90315-7

Harrison, G. J. (2015). Current controversies in diagnosis, management, and prevention of congenital cytomegalovirus: updates for the pediatric practitioner. Pediatr. Ann. 44 (5), E115-E125. doi: 10.3928/00904481-20150512-11

Harrison, R. G., MacRae, M., Karsh, J., Santucci, S., and Yang, W. H. (2015). Anaphylaxis and serum sickness in patients receiving omalizumab: reviewing the data in light of clinical experience. Ann. Allergy Asthma Immunol. 115 (1), 77-78. doi: 10.1016/j.anai.2015.04.014

Hossny, E., Rosario, N., Lee, B. W., Singh, M., El-Ghoneimy, D., Soh, J. Y., et al. (2016). The use of inhaled corticosteroids in pediatric asthma: update. World Allergy Organ J. 9, 26. doi: 10.1186/s40413-016-0117-0

Jia, J., Zhu, F., Ma, X., Cao, Z. W., Li, Y. X., and Chen, Y. Z. (2009). Mechanisms of drug combinations: interaction and network perspectives. Nat. Rev. Drug Discov. 8 (2), 111-128. doi: 10.1038/nrd2683

Khajah, M. A., Fateel, M. M., Ananthalakshmi, K. V., and Luqmani, Y. A. (2016). Anti-inflammatory action of angiotensin 1-7 in experimental colitis. PLoS One 11 (3), e0150861. doi: 10.1371/journal.pone.0150861

Khajah, M. A., Orabi, K. Y., Hawai, S., Sary, H. G., and El-Hashim, A. Z. (2019). Onion bulb extract reduces colitis severity in mice via modulation of colonic inflammatory pathways and the apoptotic machinery. J. Ethnopharmacol. 241, 112008. doi: 10.1016/j.jep.2019.112008

Lanzotti, V. (2006). The analysis of onion and garlic. J. Chromatogr. A 1112 (1-2), 3-22. doi: 10.1016/j.chroma.2005.12.016

Le Cras, T. D., Acciani, T. H., Mushaben, E. M., Kramer, E. L., Pastura, P. A., Hardie, W. D., et al. (2011). Epithelial EGF receptor signaling mediates airway hyperreactivity and remodeling in a mouse model of chronic asthma. Am. J. Physiol. Lung Cell Mol. Physiol. 300 (3), L414-L421. doi: 10.1152/ ajplung.00346.2010

Lommatzsch, M. (2012). Airway hyperresponsiveness: new insights into the pathogenesis. Semin. Respir. Crit. Care Med. 33 (6), 579-587. doi: 10.1055/s0032-1325617

Marefati, N., Eftekhar, N., Kaveh, M., Boskabadi, J., Beheshti, F., and Boskabady, M. H. (2018). The effect of allium cepa extract on lung oxidant, antioxidant, and immunological biomarkers in ovalbumin-sensitized rats. Med. Princ. Pract. 27 (2), 122-128. doi: 10.1159/000487885

Massoud, A. H., Charbonnier, L. M., Lopez, D., Pellegrini, M., Phipatanakul, W., and Chatila, T. A. (2016). An asthma-associated IL4R variant exacerbates airway inflammation by promoting conversion of regulatory T cells to TH17like cells. Nat. Med. 22 (9), 1013-1022. doi: 10.1038/nm.4147

Mondy, N., Naudin, A., Christides, J. P., Mandon, N., and Auger, J. (2001). Comparison of GC-MS and HPLC for the analysis of Allium volatiles. Chromatographia 53 (1), S356-S360. doi: 10.1007/BF02490356

Newman, D. J., and Cragg, G. M. (2016). Natural products as sources of new drugs from 1981 to 2014. J. Nat. Prod. 79 (3), 629-661. doi: 10.1021/ acs.jnatprod.5b01055

Nunes, C., Pereira, A. M., and Morais-Almeida, M. (2017). Asthma costs and social impact. Asthma Res. Pract. 3, 1. doi: 10.1186/s40733-016-0029-3

Oliveira, T. T., Campos, K. M., Cerqueira-Lima, A. T., Cana Brasil Carneiro, T., da Silva Velozo, E., Ribeiro Melo, I. C. A., et al. (2015). Potential therapeutic effect of Allium cepa L. and quercetin in a murine model of Blomia tropicalis induced asthma. Daru 23 (1), 18. doi: 10.1186/s40199-015-0098-5

O'Byrne, P. M., Barnes, P. J., Rodriguez-Roisin, R., Runnerstrom, E., Sandstrom, T., Svensson, K., et al. (2001). Low dose inhaled budesonide and formoterol in mild persistent asthma: the OPTIMA randomized trial. Am. J. Respir. Crit. Care Med. 164 (8 Pt 1), 1392-1397. doi: 10.1164/ ajrccm.164.8.2104102

Pinto, C. R., Almeida, N. R., Marques, T. S., Yamamura, L. L., Costa, L. A., and Souza-Machado, A. (2013). Local adverse effects associated with the use of inhaled corticosteroids in patients with moderate or severe asthma. J. Bras. Pneumol. 39 (4), 409-417. doi: 10.1590/S1806-37132013000400003

Plosker, G. L., and Keam, S. J. (2008). Omalizumab - a review of its use in the treatment of allergic asthma. Biodrugs 22 (3), 189-204. doi: 10.2165/00063030200822030-00005

Polosa, R., Puddicombe, S. M., Krishna, M. T., Tuck, A. B., Howarth, P. H., Holgate, S. T., et al. (2002). Expression of c-erbB receptors and ligands in the bronchial epithelium of asthmatic subjects. J. Allergy Clin. Immunol. 109 (1), 75-81. doi: $10.1067 /$ mai.2002.120274

Prescott, S., and Allen, K. J. (2011). Food allergy: riding the second wave of the allergy epidemic. Pediatr. Allergy Immunol. 22 (2), 155-160. doi: 10.1111/ j.1399-3038.2011.01145.x

Puddicombe, S. M., Polosa, R., Richter, A., Krishna, M. T., Howarth, P. H., Holgate, S. T., et al. (2000). Involvement of the epidermal growth factor receptor in epithelial repair in asthma. FASEB J. 14 (10), 1362-1374. doi: 10.1096/fasebj.14.10.1362

Queto, T., Xavier-Elsas, P., Gardel, M. A., de Luca, B., Barradas, M., Masid, D., et al. (2010). Inducible nitric oxide synthase/CD95L-dependent suppression of pulmonary and bone marrow eosinophilia by diethylcarbamazine. Am. J. Respir. Crit. Care Med. 181 (5), 429-437. doi: 10.1164/rccm.200905-0800OC

Riccio, M. M., Matsumoto, T., Adcock, J. J., Douglas, G. J., Spina, D., and Page, C. P. (1997). The effect of 15-HPETE on airway responsiveness and pulmonary cell recruitment in rabbits. Br. J. Pharmacol. 122 (2), 249-256. doi: 10.1038/ sj.bjp.0701379

Saeki, M., Nishimura, T., Kitamura, N., Hiroi, T., Mori, A., and Kaminuma, O. (2019). Potential mechanisms of T cell-mediated and eosinophil-independent bronchial hyperresponsiveness. Int. J. Mol. Sci. 20 (12), 2980. doi: 10.3390/ ijms 20122980

Seo, M. Y., Kim, K. R., Lee, J. J., Ryu, G., Lee, S. H., Hong, S. D., et al. (2019). Therapeutic effect of topical administration of red onion extract in a murine model of allergic rhinitis. Sci. Rep. 9 (1), 2883. doi: 10.1038/s41598-019-39379-9

Sherman, J., Patel, P., Hutson, A., Chesrown, S., and Hendeles, L. (2001). Adherence to oral montelukast and inhaled fluticasone in children with persistent asthma. Pharmacotherapy 21 (12), 1464-1467. doi: 10.1592/ phco.21.20.1464.34485 
Song, H. N., Jung, K. S., Yoo, K. H., Cho, J., Lee, J. Y., Lim, S. H., et al. (2016). Acquired C797S mutation upon treatment with a T790M-specific thirdgeneration EGFR inhibitor (HM61713) in non-small cell lung cancer. J. Thorac. Oncol. 11 (4), e45-e47. doi: 10.1016/j.jtho.2015.12.093

Song, L., Tang, H., Liu, D., Song, J., Wu, Y., Qu, S., et al. (2016). The chronic and shortterm effects of gefinitib on airway remodeling and inflammation in a mouse model of asthma. Cell Physiol. Biochem. 38 (1), 194-206. doi: 10.1159/000438621

Spina, D., and Page, C. (2009). Airway irritability-a burning issue? Curr. Opin. Pharmacol. 9 (4), 530-534. doi: 10.1016/j.coph.2009.06.019

Spina, D., Shah, S., and Harrison, S. (1998). Modulation of sensory nerve function in the airways. Trends Pharmacol. Sci. 19 (11), 460-466. doi: 10.1016/S01656147(98)01261-9

Takeyama, K., Fahy, J. V., and Nadel, J. A. (2001a). Relationship of epidermal growth factor receptors to goblet cell production in human bronchi. Am. J. Respir. Crit. Care Med. 163 (2), 511-516. doi: 10.1164/ajrccm.163.2.2001038

Takeyama, K., Jung, B., Shim, J. J., Burgel, P. R., Dao-Pick, T., Ueki, I. F., et al. (2001b). Activation of epidermal growth factor receptors is responsible for mucin synthesis induced by cigarette smoke. Am. J. Physiol. Lung Cell Mol. Physiol. 280 (1), L165-L172. doi: 10.1152/ajplung.2001.280.1.L165

Tamaoka, M., Hassan, M., McGovern, T., Ramos-Barbon, D., Jo, T., Yoshizawa, Y., et al. (2008). The epidermal growth factor receptor mediates allergic airway remodelling in the rat. Eur. Respir. J. 32 (5), 1213-1223. doi: 10.1183/ 09031936.00166907

Upadhyay, R. K. (2016). Nutraceutical, pharmaceutical and therapeutic uses of Allium cepa: a review. Int. J. Green Pharm. (IJGP) 10 (1), 46-64. doi: 10.22377/ ijgp.v10i1.612
Wagner, H., Dorsch, W., Bayer, T., Breu, W., and Willer, F. (1990). Antiasthmatic effects of onions: inhibition of 5-lipoxygenase and cyclooxygenase in vitro by thiosulfinates and "Cepaenes". Prostagland. Leukot. Essent. Fatty Acids 39 (1), 59-62. doi: 10.1016/0952-3278(90)90173-I

Watson, J. P., and Lewis, R. A. (1997). Is asthma treatment affordable in developing countries? Thorax 52 (7), 605-607. doi: 10.1136/thx.52.7.605

Werz, O. (2007). Inhibition of 5-lipoxygenase product synthesis by natural compounds of plant origin. Planta Med. 73 (13), 1331-1357. doi: 10.1055/s2007-990242

WHO (2019). Asthma. from http://www.who.int

Zeng, Y., Li, Y., Yang, J., Pu, X., Du, J., Yang, X., et al. (2017). Therapeutic role of functional components in Alliums for preventive chronic disease in human being. Evid. Based. Complement. Alternat. Med. 2017, 9402849. doi: 10.1155/ $2017 / 9402849$

Conflict of Interest: The authors declare that the research was conducted in the absence of any commercial or financial relationships that could be construed as a potential conflict of interest.

Copyright (C) 2020 El-Hashim, Khajah, Orabi, Balakrishnan, Sary and Abdelali. This is an open-access article distributed under the terms of the Creative Commons Attribution License (CC BY). The use, distribution or reproduction in other forums is permitted, provided the original author(s) and the copyright owner(s) are credited and that the original publication in this journal is cited, in accordance with accepted academic practice. No use, distribution or reproduction is permitted which does not comply with these terms. 